\title{
Spatial Ability: A Neglected Dimension in Talent Searches for Intellectually Precocious Youth
}

\author{
Rose Mary Webb \\ Appalachian State University
}

\author{
David Lubinski and Camilla Persson Benbow \\ Vanderbilt University
}

\begin{abstract}
Students identified by talent search programs were studied to determine whether spatial ability could uncover math-science promise. In Phase 1, interests and values of intellectually talented adolescents (617 boys, 443 girls) were compared with those of top math-science graduate students (368 men, 346 women) as a function of their standing on spatial visualization to assess their potential fit with math-science careers. In Phase 2, 5-year longitudinal analyses revealed that spatial ability coalesces with a constellation of personal preferences indicative of fit for pursuing scientific careers and adds incremental validity beyond preferences in predicting math-science criteria. In Phase 3, data from participants with Scholastic Aptitude Test (SAT) scores were analyzed longitudinally, and a salient math-science constellation again emerged (with which spatial ability and SAT-Math were consistently positively correlated and SAT-Verbal was negatively correlated). Results across the 3 phases triangulate to suggest that adding spatial ability to talent search identification procedures (currently restricted to mathematical and verbal ability) could uncover a neglected pool of math-science talent and holds promise for refining our understanding of intellectually talented youth.
\end{abstract}

Keywords: spatial ability, human capital, talent searches, math-science pipeline, individual differences

Over the past 35 years, educational opportunities for students with intellectual talent have grown, and talent identification procedures have become more sophisticated (Robinson, 1999). Before the 1970 s, the identification of students with intellectual talent was conducted largely on a case-by-case basis, if at all, and assessments were usually unidimensional, aimed at measuring general cognitive ability (cf. Achter \& Lubinski, 2003, 2005). In 1972, however, two important changes to the identification of intellectual giftedness were implemented: group testing and the assessment of specific abilities (Keating \&

This research was based on a dissertation submitted by Rose Mary Webb to Vanderbilt University in partial fulfillment of requirements for the doctor of philosophy degree. Support for this research was provided by a Research and Training Grant from the Templeton Foundation, the Strong Research Board, and National Institute of Child Health and Development Grant P30HD15052 to the John F. Kennedy Center at Vanderbilt University. Earlier versions of this article benefited from comments from Kimberley Ferriman, Gregory Park, Georgine Pion, James H. Steiger, Patrick Thompson, Jonathan Wai, and Niels G. Waller.

Correspondence concerning this article should be addressed to Rose Mary Webb, Department of Psychology, Appalachian State University, Boone, NC 28608, or to David Lubinski or Camilla Persson Benbow, Department of Psychology and Human Development, Vanderbilt University, MSC 512 Peabody Station, Nashville, TN 37203. E-mail: webbrm@appstate.edu, david.lubinski@vanderbilt.edu, or camilla .benbow@vanderbilt.edu.
Stanley, 1972; Stanley, 1996). These innovations not only enabled talent searches to identify efficiently large numbers of intellectually precocious youth in two critical areas, they simultaneously afforded a better understanding of the breadth of psychological diversity within intellectually gifted populations. The pattern and level of these abilities have been used by program developers to structure the nature and pace of the educational curriculum for mathematically and verbally precocious youth (Benbow \& Stanley, 1996; Colangelo, Assouline, \& Gross, 2004; Colangelo \& Davis, 2003; VanTassel-Baska, 1998).

Longitudinal research based on talent search participants has extended the validity of these early mathematical and verbal ability assessments to more remote time points and beyond securing educational achievements at precocious rates. The math and verbal Scholastic Aptitude Test assessments (SAT-M and SAT-V, respectively), for example, appear to inform our understanding of contrasting potentialities for creative expression and differential career development later in life (Lubinski, Benbow, Shea, Eftekhari-Sanjani, \& Halvorson, 2001; Lubinski, Webb, Morelock, \& Benbow, 2001; Park, Lubinski, \& Benbow, in press; Shea, Lubinski, \& Benbow, 2001). However, there is evidence that the level and pattern of mathematical and verbal reasoning ability provide an incomplete picture of the intellectual talent among precocious youth when spatial ability is omitted. Calculations from normal curve theory reveal that, by selecting on the basis of scores of 500 on either the SAT-M 
or SAT-V before age 13, for example, talent searches miss more than half of the top $1 \%$ in spatial ability (Lohman \& Korb, 2006; Shea et al., 2001). ${ }^{1}$ This incomplete picture limits both the creation of optimal educational opportunities for them and the modeling of their subsequent development. Indeed, as R. E. Snow (1999) observed,

There is good evidence that [visual-spatial reasoning] relates to specialized achievements in fields such as architecture, dentistry, engineering, and medicine. ... Given this plus the longstanding anecdotal evidence on the role of visualization in scientific discovery, ... it is incredible that there has been so little programmatic research on admissions testing in this domain. (p. 136)

That talent search programs, which involve more than 300,000 students annually (Lupkowski-Shoplik, Benbow, Assouline, \& Brody, 2003), have neglected this intellective dimension is especially curious, given their philosophy to develop intellectual talent across multiple dimensions, using many different kinds of learning opportunities, based on the idea that one size will never fit all (Benbow \& Stanley, 1996; Colangelo et al., 2004; Gallagher \& Gallagher, 1994; Heller, Monks, Sternberg, \& Subotnik, 2000; Stanley, 2000; VanTassel-Baska, 1998).

One study of 556 talent search participants did assess spatial ability in addition to using the SAT and, subsequently, tracked participants over 2 decades. All three specific abilities manifested incremental validity relative to the other two in the prediction of educationaloccupational outcomes 20 years later (Shea et al., 2001). Given that Shea et al.'s findings mirrored longitudinal findings from older students (Gohm, Humphreys, \& Yao, 1998; Humphreys \& Lubinski, 1996; Humphreys, Lubinski, \& Yao, 1993), the authors suggested that program developers begin to experiment with augmenting talent search selection criteria (beyond quantitative and verbal reasoning measures) with spatial ability: Educators were encouraged to think about experimenting with curriculum modifications for intellectually precocious learners especially able at nonverbal ideation, and theoreticians were encouraged to consider incorporating measures of spatial ability in longitudinal examinations of intellectually precocious youth to forestall misspecified or underdetermined causal models (cf. Lubinski, 2000).

Other longitudinal studies have evaluated the incremental validity of comprehensive preference assessments relative to SAT-M and SAT-V, not for selection, but for educational guidance and forecasting contrasting developmental trajectories. Positive results were obtained for predicting undergraduate majors 10 years later (Achter, Lubinski, Benbow, \& Eftekhari-Sanjani, 1999) and occupational group membership 20 years later (Wai, Lubinski, \& Benbow, 2005). For example, Achter et al. found that preferences explained an additional $13 \%$ of the variance in undergraduate major choices beyond the $10 \%$ offered by math and verbal abilities alone. Although these findings are informative, to our knowledge a longitudinal study involving all three specific abilities (mathematical, spatial, and verbal abilities) teamed with a comprehensive preference inventory has not appeared in the scientific literature. This leaves a gap in our knowledge and contributes to a gap in practice (Benbow \& Stanley, 1996; Colangelo et al., 2004).

This study capitalizes on a unique set of data to explicate the value of spatial ability for studying and working with intellectually precocious youth. The source of these data is a sample of adoles- cents who were enrolled in either 1-week summer enrichment classes or 3-week accelerative educational opportunities designed for mathematically or verbally precocious youth. Although all participants were well above average in general intellectual ability (all had scored in the top 3\% on at least one subtest of a conventional achievement test administered by their school), the large majority did not meet the conventional selection criteria established by most talent search programs (i.e., scoring in the top $0.5 \%$ of their age group on either mathematical or verbal reasoning ability). This provided us with a sufficiently large range of talent to test our hypotheses about an untapped talent pool. These students were assessed on spatial ability and two well-known preference inventories. Although SAT scores were not required for participation in the 1-week enrichment programs, 409 participants (38.6\%) had taken the SAT. (They earned SAT scores indicative of the top $0.5 \%$ in mathematical or verbal ability and, hence, had qualified for highly accelerated 3-week courses designed for mathematically and verbally precocious youth.) Participants were surveyed 5 years later with particular attention to their educational and occupational pursuits. Identifying the high scorers on spatial ability among all of these participants afforded a unique opportunity to study and track a group of students similar to those who could be identified if spatial ability were added to the selection criteria of modern talent search programs.

In this study, we first examine the hypothesis that a neglected pool of scientific talent would be uncovered by incorporating spatial ability into modern talent search programs. Second, we examine the hypothesis that spatial ability has the potential to refine both educational programming and conceptualize intellectually precocious youth more generally (i.e., regardless of their status on spatial ability).

This study involved three phases. Phases 1 and 2 were designed to examine the extent to which spatially talented youth display interests in and commitment to science, technology, engineering, and math (STEM) domains. If identified, would adolescents with high spatial ability be good prospects for STEM? In Phase 1, the interest and value profiles of adolescents with relatively high or low spatial ability were compared, by sex, to the profiles of math-science graduate students

\footnotetext{
${ }^{1}$ In the 9th-grade cohort of Project Talent (Flanagan et al., 1962), for example, we analyzed the quantitative and verbal reasoning ability composites that Humphreys et al. (1993) designed to mirror the SAT in conjunction with their spatial visualization composite. Within this sample $(N>100,000)$, only $30 \%$ of the top $1 \%$ on spatial ability scored within the top $1 \%$ on either mathematical or verbal reasoning. Actually, given a correlation between two variables and an assumption of bivariate normality, one can determine exactly what the loss would be for different degrees of selectivity. Lohman and Korb (2006) showed how to do this and provide tables to allow calculations at http://faculty.education.uiowa.edu/dlohman/ pdf/Gifted_today_unexpurgated.pdf. Following this reasoning, there is an important sociological corollary to adding spatial reasoning measures to talent identification procedures for intellectually precocious youth: Because the normative correlation between socioeconomic status (SES) and mathematical ability, like SES and verbal ability, is around .40, whereas the normative correlation between SES and spatial ability is around .30 (cf. Austin \& Hanisch, 1990), spatial ability measures will identify more students from lower SES levels than do verbal and mathematical abilities currently.
} 
attending top U.S. universities - individuals who had already made a commitment to pursue high-level STEM careers. In Phase 2, we conducted a series of discriminant function analyses (DFAs) to evaluate the incremental validity of spatial ability relative to that of preferences in the prediction of 5-year longitudinal criteria: favorite and least favorite high school course, leisure activities, undergraduate major, and anticipated occupation. Are there value-added benefits in assessing spatial ability beyond preferences? If so, how does spatial ability combine with preferences to predict these criteria? That is, following Ackerman (1996; Ackerman \& Heggestad, 1997) or R. E. Snow (1994; R. E. Snow, Corno, \& Jackson, 1996), respectively, what "trait clusters" or "aptitude complexes" are formed by the salient weights derived from these DFAs in the prediction of these criteria? We further examined, in Phase 2, the psychological consistency and functional equivalence of the discriminant functions derived from these five analyses by conducting a two-tiered generalization probe: First, we examined the intercorrelations among the discriminant functions uncovered to predict all five criteria, and second, we replicated these intercorrelations in an independent sample of Time 1 participants without Time 2 data. Following Lykken's (1968) nomenclature for conducting replications in psychological research, the latter constitutes a "literal replication." Finally, in Phase 3, we conducted a similar series of DFAs for those Phase 2 participants with SAT scores to assess the incremental validity of spatial ability beyond preferences and the SAT in the prediction of the same longitudinal criteria as in Phase 2. This last phase of our study tested the hypothesis that spatial ability is a valuable addition to talent search programs for all participants-even those who qualify for accelerative learning opportunities based on their quantitative or verbal abilities. And, as in Phase 2, these discriminant functions were examined to ascertain how spatial ability combines with preferences and the SAT to predict these criteria, or what trait clusters or aptitude complexes are formed by the salient weights derived from these analyses. In the final component of Phase 3, we again conducted a two-tiered generalization probe: We examined the intercorrelations among the discriminant functions uncovered here to predict all five criteria to evaluate their conceptual equivalence and empirical interchangeability, and then we replicated these intercorrelations using the sample of Time 1 participants who were assessed on all their abilities and preferences but for whom there were no Time 2 data as another literal replication. These three phases were designed to triangulate to increase confidence in inferences drawn from the findings.

\section{Method}

\section{Participants}

Participants were drawn from the Study of Mathematically Precocious Youth (SMPY), a longitudinal study of the development of intellectual talent throughout the lifespan (Lubinski \& Benbow, 2006; Stanley, 1996). A comparison group of mathematics, science, and engineering graduate students was also included in the first phase of our study. Each of these samples is described in more detail below.

Talent search participants. SMPY participants in this study were drawn primarily from the Midwest (from 1992 to 1997) and had scored at or above the 97th percentile on any subtest of the standardized achievement tests routinely administered in their schools. The sample consisted of 7th-, 8th-, 9th-, and 10th-grade students $(31 \%, 37 \%, 24 \%$, and $8 \%$, respectively). Because identification was based on high performance on any single subtest rather than on a composite score, many participants with composite scores well below the 97th percentile in both quantitative and verbal reasoning were included. All students had participated in either a 1-week summer enrichment program or a 3-week accelerative educational opportunity for mathematically or verbally precocious youth. The latter had taken the SAT and qualified as being in the top $0.5 \%$ on mathematical or verbal reasoning ability.

Although some participants were identified by scoring highly on the SAT, our sample included many adolescents who did not necessarily take the SAT even though they were qualified to do so according to their initial screening based on their grade-level test scores. These participants represented a broader range of talent than those who score highly on the SAT through talent search programs. This more intellectually diverse sample was ideal for this study inasmuch as it allowed us to identify many spatially talented students who would be missed by conventional talent search programs that use high cutting scores on the SAT to select students for educational programming. Moreover, the heterogeneity of this sample provides an opportunity to compare intellectually able students with high spatial abilities to intellectually able students with relatively low spatial abilities to determine the extent to which high spatial ability identifies students with potential for STEM careers.

At Time 1, Phase 1 (approximately age 13), 1,060 participants (617 boys, 443 girls) were assessed (88\% White, 8\% Asian, 1\% Black, $2 \%$ other, and $1 \%$ unknown race/ethnicity). Although SAT scores were not required for participation, 409 participants had taken the SAT. At Time 2, Phases 2 and 3 (approximately 5 years later at age 18), participants were surveyed by mail. Approximately $93 \%$ of the original participants were located for this 5-year follow-up. Follow-up questionnaires were returned by 547 participants (281 men, 266 women); overall response rate was $52 \%$ ( $57 \%$ corrected for lost and deceased). For a generalization probe, the Time 1 data of the nonrespondents to the longitudinal survey were used to replicate the covariance structure uncovered in analyses based on participants with data at both time points.

Graduate student participants. In 1992, SMPY identified and studied graduate students enrolled in the top 15 U.S. mathematics, science, and engineering programs and who had made a commitment to STEM careers. Most were completing their 1st or 2nd year of graduate studies. These graduate students were some of the nation's most able scientists-in-training. ${ }^{2}$ Because men outnumbered women in many programs but equivalent representation by sex was sought for this sample, women were oversampled by identifying all qualifying women in each department and selecting an equal number of men randomly. This oversampling of women resulted in 368 men and 346 women, a total of 714 participants (for further details, see Lubinski, Benbow, et al., 2001).

\footnotetext{
${ }^{2}$ Their Graduate Record Exam (GRE) scores may be used as one benchmark of their ability level: Mean scores on the GRE-Verbal were $622.3(S D=87.4)$ for men and $615.5(S D=99.1)$ for women; on the GRE-Quantitative, they were $747.6(S D=60.3)$ for men and $734.4(S D=$ 58.0) for women; and on the GRE-Analytic, they were $701.5(S D=87.3)$ for men and $711.0(S D=79.1)$ for women.
} 


\section{Instruments for Talent Search Participants}

Data from Cattell's (1957) three major sources (tests, questionnaires, and life records) were collected, using both normative and idiographic methods. At Time 1, participants completed a background questionnaire, and their cognitive abilities and personal preferences were assessed. At Time 2, participants completed a follow-up survey.

Abilities. The Mental Rotation Test (Vandenberg \& Kuse, 1978) assesses three-dimensional spatial visualization. The test consists of 20 multiple-choice items in which the examinee matches a criterion figure to two of four response options. Two response options are correct, identical to the criterion but rotated in space, whereas the other two response options are incorrect, including one mirror image of the criterion and one rotated image from another test item. The test was administered with a 10-min time limit. Test-retest reliabilities over 1 year were .83 and .70 for two samples (Kuse, 1977), and internal consistency reliability was .88 for the original standardization sample (Vandenberg \& Kuse, 1978). Schmidt, Lubinski, and Benbow (1998) found the 1 -year test-retest reliability of this instrument was .73 for intellectually talented adolescents.

The Mechanical Comprehension Test (Bennett, 1969) assesses the understanding of the relationships of mechanical elements and physical forces in practical settings. It consists of 68 multiple-choice items, each of which includes three response options, only one of which is correct. Each item requires the examinee to make a judgment about a pictorially represented practical or mechanical situation. The test was administered with a 30-min time limit. Bennett reported a split-half reliability of .84 for a sample of 9th-grade boys. Test-retest reliability over 1 year was .85 for intellectually talented boys and girls (Schmidt et al., 1998).

The SAT was designed as a college entrance exam for college-bound high school juniors and seniors but is widely used as an above-level testing procedure in talent searches across the United States (Benbow \& Stanley, 1996; Colangelo $\&$ Davis, 2003). Because talent search students are originally identified by scoring at or near the ceiling of their gradenormed standardized achievement tests (e.g., the Iowa Test of Basic Skills), little differentiation among them on the basis of those scores alone is possible. However, these students generate score distributions on the SAT that are practically indistinguishable from those generated by students $4-5$ years older (Barnett \& Gilheany, 1996; Benbow, 1988; Wendler, Ninneman, \& Feigenbaum, 2001), allowing for more precise appraisals of their cognitive development. The reliability of the SAT in talent search samples has been examined frequently (Benbow \& Wolins, 1996; Brody \& Benbow, 1990; Minor \& Benbow, 1996); for example, in a comparison of the SAT-M's item difficulty patterns of almost 9,000 7th-grade talent search participants and more than 7,000 high school students, the correlation between the item difficulties of these two groups was .95 (Benbow \& Wolins, 1996). Moreover, for intellectually precocious young adolescents, the SAT has demonstrated predictive validity for multiple academic criteria (Benbow, 1992; Bleske-Rechek, Lubinski, \& Benbow, 2004; Colangelo et al., 2004; Lubinski, Webb, et al., 2001; Shea et al., 2001), as well as for occupa- tional success and creativity (Benbow, Lubinski, Shea, \& Eftekhari-Sanjani, 2000; Lubinski, Benbow, Webb, \& BleskeRechek, 2006; Park et al., in press; VanTassel-Baska, 1998; Wai et al., 2005).

Preferences. The Study of Values (SOV; Allport, Vernon, \& Lindzey, 1970) assesses ipsatively the relative prominence of personality-related values based on Spranger's (1928) six types: theoretical (discovery of truth), economic (utility and practical knowledge), aesthetic (form and harmony), social (love of others), political (power), and religious (unity and meaning). Following its 1970 revision, it was the third most frequently cited nonprojective personality test in use, but its use has declined greatly over the past 2 decades, largely due to the dated and noninclusive language in some items. We addressed this issue by slightly updating the language in a few questions, which did not appear to attenuate its reliability or validity (see below). However, Kopelman, Rovenpor, and Guan (2003) have modernized the instrument in a recent revision, which has displayed similar psychometric properties to the 1970 version.

The Strong Interest Inventory (SII; Hansen \& Campbell, 1985) assesses interests relevant to educational choice and occupational satisfaction (Dawis, 1991; Harmon, 1989; R. E. Snow et al., 1996). The SII is arranged according to Holland's $(1996,1997)$ hexagonal model; adjacent themes are more highly correlated to one another, whereas opposite themes are the least correlated. This structure is commonly referred to as "RIASEC," an acronym for each of the six general occupational themes defining the hexagon: realistic (working with things and tools), investigative (scientific pursuits), artistic (aesthetic pursuits and self-expression), social (contact with and helping people), enterprising (buying, marketing, and selling), and conventional (office practices and well-structured tasks). RIASEC has emerged repeatedly in large and diverse samples, its generalizability has held up cross-culturally (Day \& Rounds, 1998; Day, Rounds, \& Swaney, 1998; J. Rounds \& Tracey, 1996; J. B. Rounds \& Armstrong, 2005), and the dimensions remain relatively stable throughout adolescence (Low, Yoon, Roberts, \& Rounds, 2005).

The SII also contains 23 basic interest scales that provide finer distinctions among educational and occupational interests than the six broad themes permit (Armstrong, Smith, Donnay, \& Rounds, 2004). The basic interest scales include Agriculture, Nature, Adventure, Military Activities, Mechanical Activities, Science, Mathematics, Medical Science, Medical Service, Music/Dramatics, Art, Writing, Teaching, Social Service, Athletics, Domestic Arts, Religious Activities, Public Speaking, Law/Politics, Merchandising, Sales, Business Management, and Office Practices. To differentiate between the two organizational levels of the SII, general occupational themes and basic interest scales are referred to as RIASEC and BIS, respectively.

Although both preference instruments used in the current study were originally designed for older populations, the psychometric properties of each have been examined for intellectually precocious youth in a series of studies. These preference assessments have manifested longitudinal stability: Schmidt et al. (1998) observed 1-year test-retest correlations for the SOV scales averaging .70 (range $=.63-.79)$ and estimates based on RIASEC and BIS averaging .77 (range $=.74-.80$ ). Mean test-retest correlations of .41 and .42 over 15 years (ages 13-28) have been observed for the RIASEC and BIS scales, respectively (Lubinski, Benbow, \& Ryan, 1995), and the mean 
test-retest correlation across the six dimensions of the SOV over 20 years (ages 13-33) was .37 (Lubinski, Schmidt, \& Benbow, 1996). Examinations of the construct validity of these two preference instruments revealed convergent and discriminant correlational patterns to external criteria similar to those in adult samples (Schmidt et al., 1998). Moreover, as reviewed earlier, preference instruments have exhibited predictive validity in educational (Achter et al., 1999) and occupational contexts (Wai et al., 2005).

Background questionnaire. Participants completed a 10-page background questionnaire, which included demographic, familial, attitudinal, educational, and social activity items, as well as questions about their educational and vocational plans.

After high school follow-up survey. During their first year of college, participants completed a follow-up survey, which consisted primarily of questions about high school experiences and future educational and vocational plans. Criterion variables examined in the longitudinal components (Phases 2 and 3) were drawn from this survey.

\section{Instruments for Graduate Student Participants}

Graduate students were assessed on the SOV, the SII, and a background questionnaire. The latter surveyed achievements, education, home experiences, occupational goals, and personal views (Lubinski, Benbow, et al., 2001).

\section{Design and Analysis}

In Phase 1, the nonintellectual attributes of intellectually talented adolescents in the bottom versus top quartile of spatial ability were compared, by sex, with those of graduate students enrolled in top mathematics, science, and engineering programs. In Phase 2, a series of DFAs was used to evaluate the incremental validity of spatial ability, relative to preferences, in the prediction of educational-vocational outcomes over 5 years (favorite and least favorite high school course, leisure activities, undergraduate major, and anticipated occupation). Finally, in Phase 3, the same criteria used in Phase 2 were used in a series of DFAs to ascertain the incremental validity of spatial ability, relative to preferences and mathematical and verbal abilities, for the subset of Phase 2 participants with SAT scores (i.e., the gifted youth who had been identified using traditional methods)

Phase 1: Comparing Spatially Talented Adolescents and Math-Science Graduate Students-Procedure and Results

A spatial composite was derived by standardizing, within grade, scores on the two spatial measures, the Mental Rotation Test and the Mechanical Comprehension Test. These scores were then averaged for each participant to yield a spatial composite score. High and low spatial ability comparison groups were determined on the basis of the highest $25 \%$ and the lowest $25 \%$ of each grade, by sex, to form high spatial ability (high-space) groups (154 males, 110 females) and low spatial ability (low-space) groups (154 males, 112 females). This procedure led to high- and low-space groups, within sex, that were distinguished by at least a full standard deviation on the spatial composite. However, consistent with sex differences in spatial ability observed in the general population (Geary, 1998, 2004; Halpern, 2000; Hedges \& Nowell, 1995; Kimura, 1999; LoringMeier \& Halpern, 1999; Lubinski \& Humphreys, 1990; Masters, 1998; Parsons et al., 2003), males exhibited higher spatial abilities than females, overall. To illustrate this difference, we compared the lower bound of the spatial ability composite for the high-space females (75th percentile within sex) with the upper bound for the low-space males (25th percentile within sex) and found a mere .03 standard deviation unit difference between the cutoffs.

\section{Descriptive Statistics}

Intellectually able students with high versus low standing on spatial ability were hypothesized to manifest distinct constellations of nonintellectual attributes specifically indicative of fit for math-science careers. Therefore, among the sample of talent search participants, the top and bottom quartiles of spatial ability were profiled, by sex, along the six SOV dimensions and the two levels of generality of the SII (RIASEC and BIS) and compared with the graduate student profiles in Figures 1, 2, and 3. As anticipated, high-space groups, regardless of sex, exhibited high theoretical values: Both male and female highspace groups were well above the normative mean on the theoretical dimension; however, the male high-space adolescents were particularly distinguished by their standing on this value (nearly a full standard deviation above the normative mean of 40). Although findings from the RIASEC themes were ambiguous across sex, a clear pattern emerged for both males and females on the BIS, which is especially relevant to the overarching hypothesis under scrutiny: Relative to low-space adolescents and regardless of sex, high-space adolescents exhibited salient interests in science, mathematics, and mechanical activities.

\section{Profile Similarity}

We hypothesized that, if using spatial ability in talent search programs identifies a group of students with promise for STEM, then male and female high-space adolescents should exhibit educationally and vocationally relevant personal preferences more similar to their same-sex graduate student counterparts than would the low-space adolescents. An extensive literature reveals that individuals with the same preference profiles tend to aggregate in similar careers (Dawis, 1991; Dawis \& Lofquist, 1984; Hansen \& Campbell, 1985; Harmon, 1989; R. E. Snow et al., 1996).

Rather than contrasting individual preference dimensions or comparing profiles using one of many congruence coefficients (e.g., C index [Brown \& Gore, 1994] or $r_{c}$ [Gorsuch, 1983]), we compared mean SOV, RIASEC, and BIS profiles of high- and low-space groups with the mean profiles of the graduate students, by sex, using generalized distances in $n$-dimensional space. Because the themes within each preference measure are not orthogonal, Mahalanobis, rather than Euclidean, distance measures were preferable here because they take into account the covariation among the profile's constituent dimensions. 

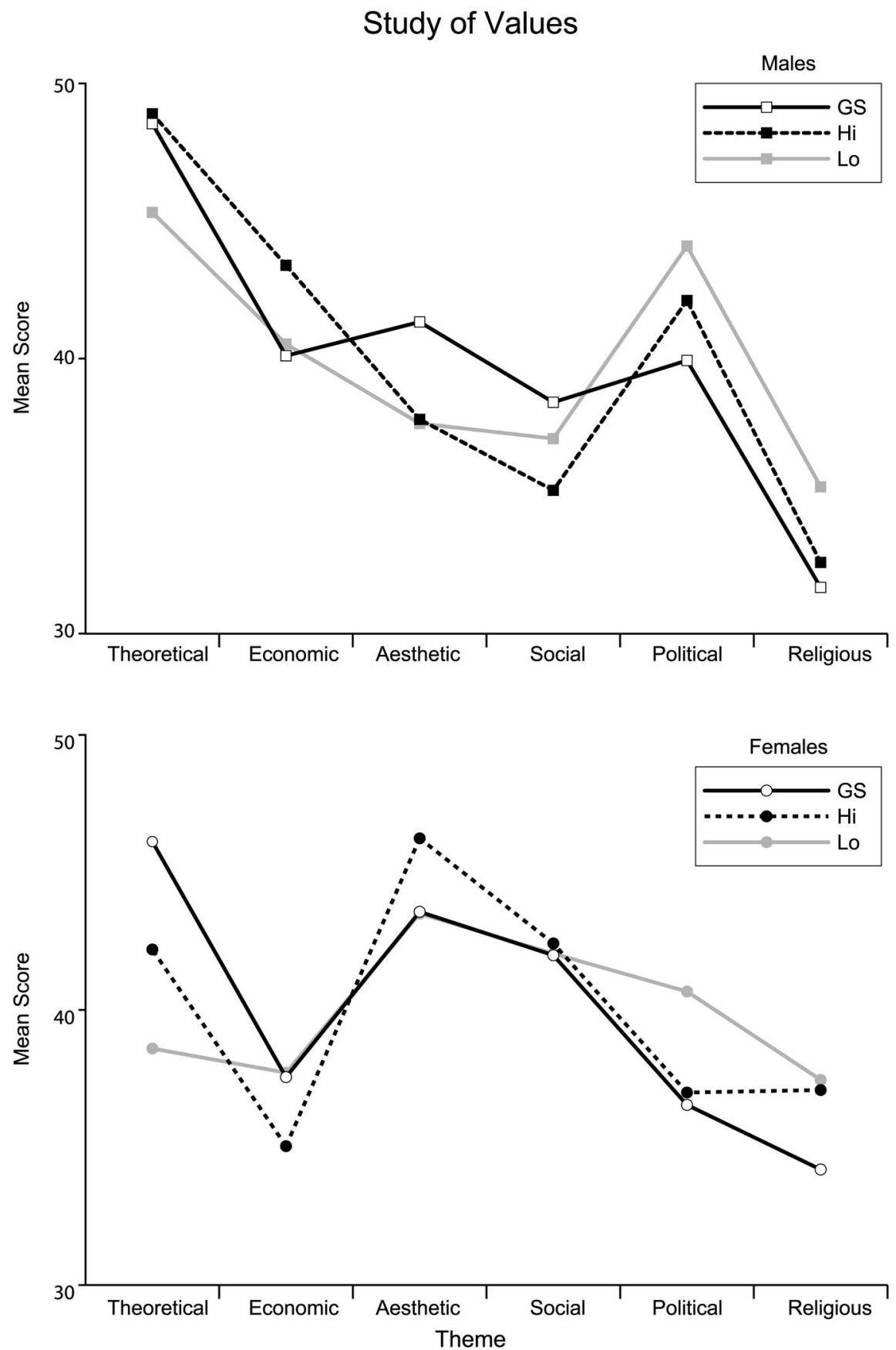

Figure 1. Study of Values (SOV). Means on the SOV for extreme spatial groups and graduate student comparison groups, by sex. GS = graduate students; $\mathrm{Hi}=$ high spatial ability adolescents; Lo = low spatial ability adolescents.

Cronbach and Gleser (1953) recommended the use of a Mahalanobis distance for correlated variates (especially for evaluating the profile similarity between groups), explaining that it "yields the same results as would be obtained if one factored the correlation matrix into $k$ orthogonal factors, computed the person's scores on these components, and then applied the [Euclidean distance] formula to measure similarity" (p. 467).
To test the hypothesis that the high-space adolescents are more similar to their gender-equivalent graduate student counterparts than are the low-space adolescents, generalized distances between each extreme space group's mean profile and the same-sex graduate student mean profile were calculated for SOV, RIASEC, and BIS dimensions. Rather than directly examining the absolute differences between the profiles of 


\section{Strong Interest Inventory General Occupational Themes}
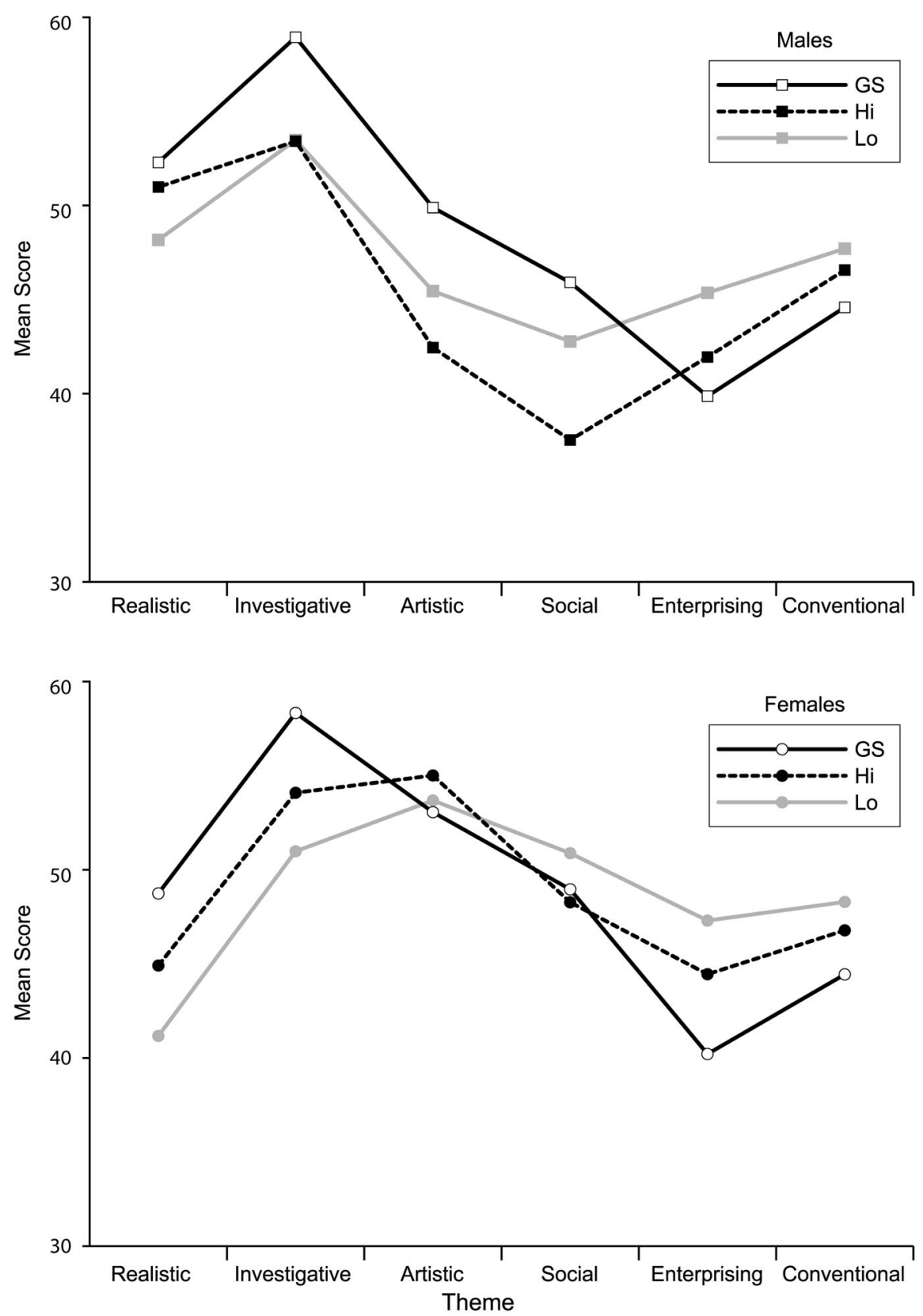

Figure 2. Strong Interest Inventory general occupational themes. Means on the RIASEC for extreme spatial groups and graduate student comparison groups, by sex. RIASEC = general occupational themes of Strong Interest Inventory; GS = graduate students; $\mathrm{Hi}=$ high spatial ability adolescents; Lo = low spatial ability adolescents. 


\section{Strong Interest Inventory Basic Interest Scales}
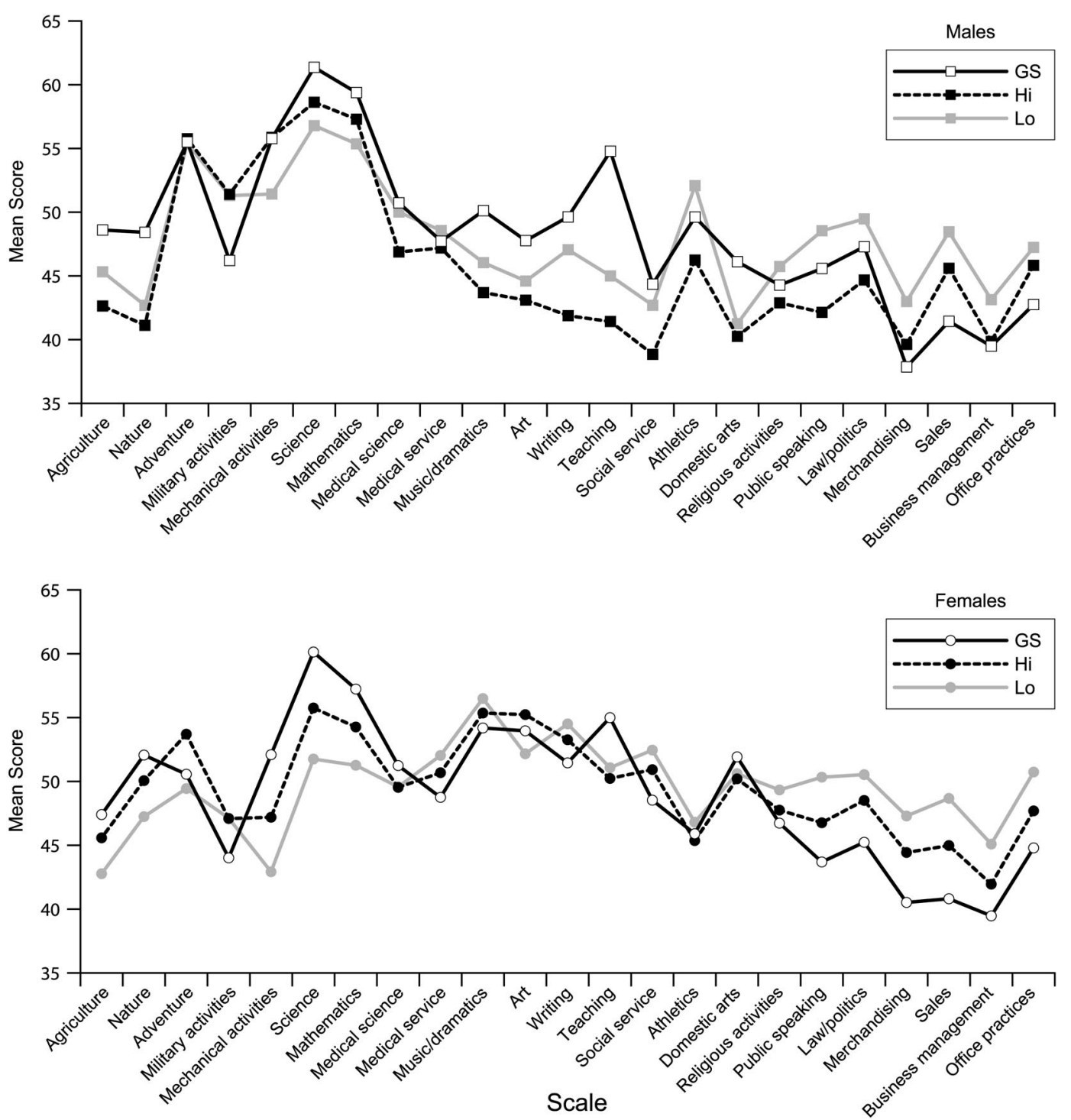

Figure 3. Strong Interest Inventory Basic Interest Scales (BIS). Means on the BIS for extreme spatial groups and graduate student comparison groups, by sex. GS = graduate students; $\mathrm{Hi}=$ high spatial ability adolescents; Lo $=$ low spatial ability adolescents.

adolescents and graduate students, we examined the relative similarity between each of the adolescent groups and the graduate students. Therefore, the difference between pairs of generalized distances was calculated by squaring the difference between the Mahalanobis distances (i.e., the positive square roots of each relevant Mahalanobis squared distance) in each comparison, by sex. Because Mahalanobis squared distances are distributed as an $F$ distribution (Bose \& Roy, 1938; Roy, 1938), the statistical significance of each squared distance (or squared distance between pairs of squared dis- tances, as we have here) may be tested using a standard $F$ test (Cacoullos, 1962; Rao, 1948).

High-space girls, as compared with low-space girls, exhibited more similar profiles to the graduate students on the SOV, $F(5$, $208)=5.99, p<.01$; the RIASEC, $F(6,180)=10.50, p<.01$ and the BIS, $F(23,163)=20.26, p<.01$. However, although the direction of the comparisons was in the predicted direction for each of the measures, there were no statistically significant differences for the boys between the profile similarities of each 
space group to the graduate students: $\mathrm{SOV}, F(5,286)=1.63, n s$; RIASEC, $F(6,244)=0.02, n s$; and BIS, $F(23,227)=0.92, n s^{3}$

Phase 2: Incremental Validity of Spatial Ability Relative to Preferences in Longitudinal Forecasts-Procedure and Results

The differences in nonintellectual attributes between high-space and low-space intellectually able adolescents observed in Phase 1 were expected to portend individual differences in temporally remote developmental choices and outcomes. Participants' group memberships for five longitudinally assessed criterion variables (favorite and least favorite high school course, leisure activities, undergraduate majors, and anticipated occupations) were categorized to examine the validity of spatial ability using the group membership approach (Humphreys et al., 1993; Rulon, Tiedmen, Tatsuoka, \& Langmuie, 1967; Tatsuoka, 1988). C. P. Snow's (1965) "two cultures," further informed by Ackerman's (1996; Ackerman \& Heggestad, 1997) science-math and intellectualcultural "trait clusters," provides the rationale for isolating constellations of personal attributes as indicative of humanists (intellectually talented but with low spatial ability) and scientists (intellectually talented and with high spatial ability). Therefore, participants' group memberships for each of the criterion variables (e.g., undergraduate major) were split into three groups (sciencemath, humanities, or other). Frequencies of how participants fell into the three categories for each of the five primary criterion variables, by sex, appear in Table 1 .

To test the hypothesis that spatial ability provides incremental validity (Sechrest, 1963) over preferences (values or interests) in the prediction of group membership, we performed a series of hierarchical DFAs. The five criterion variables served in two series of 5 DFAs: The first series used values and spatial ability; the second series included interests and spatial ability. In the first 5 DFAs, five of the six scales of the SOV were entered in the first step (because the SOV is ipsative, the sixth scale is redundant and was therefore eliminated from the analysis), and the spatial composite was added in the second step. Next, each of these analyses was repeated using the six RIASEC themes in the first step and the spatial composite in the second step. The incremental validity of spatial ability was assessed by examining the difference in the proportion of variance explained at each step; that is, the difference between Pillai's trace estimates of the preferenceplus-spatial ability model and the preference-alone model. Summary information for each of these models appears in Table 2. In all 10 DFAs, spatial ability provided a statistically significant improvement over preferences alone in predicting whether favorite and least favorite high school course, leisure activities, undergraduate major, and anticipated occupation were in math-science, humanities, or in other groups by explaining an additional $1 \%-5 \%$ of the variance in group membership. ${ }^{4}$

Because spatial ability consistently exhibited incremental validity over preferences in the prediction of group membership criteria, we examined the discriminant function structure matrices directly. Although many methodological approaches do not allow for a direct interpretation of variables, the structure matrix of a DFA affords an opportunity to examine the relationship of each variable with the composite function. Each structure matrix includes, for each function, a vector of correlations between scores on that
Table 1

Number of Participants Reporting Science-Math, Humanities, or Other Developmental Choices and Preferences Along Five Criterion Variables

\begin{tabular}{lrrrrr}
\hline Participants & Fav. & Least & Leis. & Major & Occ. \\
\hline Male & & & & & \\
$\quad$ Science-math & 144 & 99 & 48 & 176 & 96 \\
Humanities & 102 & 129 & 76 & 41 & 14 \\
Other & 35 & 49 & 156 & 53 & 118 \\
Female & & & & & \\
Science-math & 92 & 120 & 2 & 105 & 43 \\
Humanities & 144 & 92 & 101 & 57 & 13 \\
Other & 30 & 51 & 158 & 88 & 159 \\
\hline
\end{tabular}

Note. Fav. = favorite course, Least = least favorite course, Leis. = preferred leisure activity, Major = undergraduate major, and Occ. = anticipated occupation.

discriminant function and each predictor variable. Thus, they may be examined directly for content and can be psychologically interpreted (Betz, 1987).

We hypothesized, for DFAs based on spatial ability and the SOV, that spatial ability, theoretical values, and reversed social values would define a function that discriminated members of the science-math criterion groups from the humanities and other groups of participants along the developmentally sequenced series of external criteria. Similarly, we hypothesized, for DFAs based on spatial ability and RIASEC, that spatial ability and investigative,

\footnotetext{
${ }^{3}$ To further evaluate profile similarity (using a more traditional procedure), mean graduate student profiles were correlated with each of the extreme space groups, by sex, on each of the three preference measures. For males, the correlations between the mean profiles of graduate students and high-space adolescents were $.90, .73$, and .72 for the SOV, RIASEC, and BIS, respectively, whereas the correlations between the mean profiles of graduate students and low-space adolescents were $.91, .76$, and .69 , respectively. For females, however, these correlations were more divergent: The mean profiles of graduate students and high-space adolescents covaried $.78, .85$, and .86 for the SOV, RIASEC, and BIS, respectively, whereas the correlations between the mean profiles of graduate students and low-space adolescents were $.55, .42$, and .46 , respectively. This pattern was very similar to that observed using Mahalanobis squared distances: more similar profiles between graduate student and high-space females than between graduate student and low-space females, but ambiguous results for the males. Mahalanobis squared distances and correlations based on medians, rather than means, were also calculated, and the pattern of results was similar to that based on means. Because there was no clear advantage to the median-based method for either set of analyses, these findings are not presented here but are available from the authors on request.

${ }^{4}$ Some specific preference-ability interactions were hypothesized and tested (viz., for the SOV, Theoretical $\times$ Spatial and Social $\times$ Spatial; for the RIASEC, Investigative $\times$ Spatial, Realistic $\times$ Spatial, and Social $\times$ Spatial). Although a few reached statistical significance due to the large sample size and the number of criterion variables examined, the additional variance explained by their inclusion was inconsequential; therefore, we did not investigate them further. Although the theory of work adjustment (Dawis \& Lofquist, 1984; Lofquist \& Dawis, 1991) predicts interactions between satisfaction and satisfactoriness, corresponding interactions between preferences and ability were not identified in this study. These findings are reminiscent of Dawes's (1979; Dawes \& Corrigan, 1974) observation regarding the "robust beauty of linear models."
} 
Table 2

Incremental Validity of Spatial Ability Beyond Preferences in Discriminant Function Analyses (DFAs)

\begin{tabular}{|c|c|c|c|c|c|c|c|}
\hline $\begin{array}{c}\text { Values + Spatial } \\
\text { Ability }\end{array}$ & Pillai's trace & $\Delta$ & $p$ & $\begin{array}{c}\text { Interests }+ \text { Spatial } \\
\text { Ability }\end{array}$ & Pillai's trace & $\Delta$ & $p$ \\
\hline Favorite course & & & & Favorite course & & & \\
\hline SOV & .11 & & & RIASEC & .16 & & \\
\hline $\mathrm{SOV}+\mathrm{S}$ & .14 & .02 & .01 & RIASEC $+\mathrm{S}$ & .18 & .01 & .05 \\
\hline Least favorite course & & & & Least favorite course & & & \\
\hline SOV & .06 & & & RIASEC & .11 & & \\
\hline $\mathrm{SOV}+\mathrm{S}$ & .10 & .05 & .0001 & RIASEC $+\mathrm{S}$ & .14 & .02 & .01 \\
\hline Preferred leisure activity & & & & Preferred leisure activity & & & \\
\hline SOV & .08 & & & RIASEC & .13 & & \\
\hline $\mathrm{SOV}+\mathrm{S}$ & .11 & .03 & .001 & RIASEC $+S$ & .14 & .02 & .03 \\
\hline Undergraduate major & & & & Undergraduate major & & & \\
\hline SOV & .20 & & & RIASEC & .26 & & \\
\hline $\mathrm{SOV}+\mathrm{S}$ & .23 & .03 & .01 & RIASEC $+\mathrm{S}$ & .28 & .02 & .01 \\
\hline Anticipated occupation & & & & Anticipated occupation & & & \\
\hline SOV & .15 & & & RIASEC & .15 & & \\
\hline $\mathrm{SOV}+\mathrm{S}$ & .18 & .04 & .0001 & RIASEC $+\mathrm{S}$ & .17 & .03 & .01 \\
\hline
\end{tabular}

Note. The first row of each set of two rows reports the Pillai's trace statistic (explained variance) for the DFA based on preferences alone; the second reports Pillai's trace for the DFA based on preferences and spatial ability, the incremental validity of the second model $(\Delta)$, and the $p$ value of the significance test for additional variance explained. Values of delta may not equal the differences between reported Pillai's trace statistics due to rounding. SOV $=$ Study of Values; RIASEC $=$ general occupational themes of Strong Interest Inventory; S = spatial ability.

realistic, and reversed social interests would define a function that discriminated members of the science-math criterion groups from the other two groups along the external criterion variables described above. A second function, defined largely by aesthetic values (on the SOV) or artistic interests (on the RIASEC), was expected to discriminate members of the humanities groups from other groups on the criterion variables.

The first function $\left(\mathrm{F}_{1}\right)$ of each of the DFAs based on values and spatial ability, regardless of criterion variable, consistently exhibited strong positive correlations with spatial ability (mean $r=.73$ ) and theoretical values (mean $r=.65$ ) and consistent negative correlations with social values (mean $r=-.42$ ), as hypothesized (see Table 3). In addition, the first functions exhibited consistent positive correlations with economic values (mean $r=.56$ ) and negative correlations with aesthetic values (mean $r=-.53$ ). Similarly, for DFAs based on interests and spatial ability, $\mathrm{F}_{1}$ exhibited strong positive correlations with spatial ability (mean $r=.65$ ) and consistent negative correlations with social interests (mean $r=-.46$ ) for all criterion variables, as predicted, and consistent negative correlations with artistic interests (mean $r=$ -.57). Although the hypothesized positive correlations with investigative (mean $r=.22$ ) and realistic interests (mean $r=.31$ ) were smaller, the first functions appear to draw on a constellation of personal attributes that are conducive to math-science pursuits. No pattern was clear for $\mathrm{F}_{2}$; in fact, although statistically significant (due to the large sample size), very little additional variance was explained by any of the second functions.

The conceptual equivalence and empirical interchangeability of the first functions across all analyses were evaluated by correlating participants' scores on these functions. Discriminant function scores may be calculated by multiplying participants' scores on each variable in the function by that variable's corresponding discriminant function weight and summing them. Scores on each discriminant function were calculated for all talent search participants, whether or not longitudinal data were available for them. The intercorrelations among the function scores (across the five different analyses of each set) were consistently high (see Appendix A, Table A1). The average intercorrelation among the first functions $\left(\mathrm{F}_{1}\right)$ based on the SOV and spatial ability was $.90(S D=.05)$ for the subsample with longitudinal data and $.91(S D=.05)$ for the replication subsample without longitudinal data; the average intercorrelation among the first functions based on the RIASEC and spatial ability was .79 for both subsamples $(S D=.15$ for those with longitudinal data; $S D=.16$ for those without longitudinal data). The second functions were markedly less robust, exhibiting much lower and more variable intercorrelations. Because the integrity of both sets of second functions $\left(\mathrm{F}_{2}\right)$ was more frail, attention was focused on the covariance structure of $F_{1}$ across both sets of five DFAs.

Overall, the first functions $\left(\mathrm{F}_{1}\right)$ of each of the two sets of five DFAs appear functionally equivalent and empirically interchangeable, regardless of the criterion variable used (favorite course, least favorite course, preferred leisure activities, undergraduate major, or anticipated occupation). This observed pattern of uniformly high intercorrelations among the first functions implies that they were converging on the same criterion space.

In addition to the first functions drawing on the same constellation of traits to forecast external criteria with comparable precision, they do so across preference instruments (SOV or RIASEC). To quantify this generalization, participants' scores on the first functions derived from the DFAs based on the SOV and spatial ability were correlated with participants' scores on the first functions derived from the DFAs based on the RIASEC and spatial ability (Appendix A, Table A2). The correlations among the scores on the first functions across instruments averaged $70(S D=.05)$ among participants for whom longitudinal data were available and 
Table 3

Two Sets of Discriminant Functions (Values + Spatial Ability and Interests + Spatial Ability) for Five Criterion Variables Across Three Criterion Groups (Science-Math, Humanities, Other)

\begin{tabular}{|c|c|c|c|c|c|c|c|c|c|c|}
\hline \multirow[b]{2}{*}{ Dimension } & \multicolumn{5}{|c|}{$\mathrm{F}_{1}$} & \multicolumn{5}{|c|}{$\mathrm{F}_{2}$} \\
\hline & Fav. & Least & Leis. & Major & Occ. & Fav. & Least & Leis. & Major & Occ. \\
\hline \multicolumn{11}{|c|}{ Values + Spatial Ability } \\
\hline Theoretical & .69 & .49 & .61 & .71 & .73 & .48 & .06 & .42 & .25 & -.03 \\
\hline Economic & .72 & .39 & .69 & .52 & .57 & .08 & -.60 & -.53 & -.63 & -.56 \\
\hline Aesthetic & -.60 & -.55 & -.34 & -.61 & -.56 & .46 & .20 & .52 & .59 & .32 \\
\hline Social & -.46 & -.24 & -.51 & -.39 & -.50 & -.67 & .56 & -.07 & .12 & .40 \\
\hline Religious & -.38 & -.03 & -.46 & -.07 & -.16 & -.39 & .43 & .07 & .02 & -.00 \\
\hline Spatial ability & .68 & .87 & .79 & .62 & .70 & -.04 & -.11 & .23 & .41 & -.62 \\
\hline Pillai's trace & .13 & .09 & .09 & .17 & .17 & .01 & .01 & .02 & .06 & .01 \\
\hline \multicolumn{11}{|c|}{ Interests + Spatial Ability } \\
\hline Realistic & .30 & .35 & -.04 & .51 & .42 & .31 & .58 & -.28 & .24 & .05 \\
\hline Investigative & .24 & .31 & -.26 & .55 & .27 & -.53 & .00 & -.27 & .38 & .47 \\
\hline Artistic & -.72 & -.45 & -.66 & -.52 & -.51 & -.32 & -.29 & .51 & .67 & .69 \\
\hline Social & -.41 & -.19 & -.87 & -.22 & -.60 & .15 & .17 & .04 & -.03 & .52 \\
\hline Enterprising & -.18 & -.14 & -.55 & -.14 & -.24 & .34 & .34 & -.39 & -.14 & .13 \\
\hline Conventional & .31 & .49 & -.27 & .35 & .19 & .16 & -.07 & -.03 & -.09 & .47 \\
\hline Spatial ability & .61 & .66 & .64 & .59 & .75 & -.18 & .25 & -.15 & .38 & .19 \\
\hline Pillai's trace & .15 & .12 & .10 & .19 & .16 & .03 & .02 & .04 & .09 & .02 \\
\hline
\end{tabular}

Note. Correlations reflect the structure matrices (i.e., correlations between function scores and scores on each preference dimension) of discriminant function analyses based on a preference measure (either SOV or RIASEC) and spatial ability with favorite course (Fav.), least favorite course (Least), preferred leisure activity (Leis.), undergraduate major (Major), and expected occupation (Occ.) as the criterion variables. The proportion of variance in group membership (science-math, humanities, or other) explained by each function (Pillai's trace) is reported for each function. $\mathrm{F}_{1}=$ first discriminant function, $\mathrm{F}_{2}=$ second discriminant function.

replicated among participants for whom longitudinal data were not available, averaging .71 $(S D=.06)$.

Finally, to illustrate the psychological space that each of the three criterion groups occupy along the first functions, participants' function scores were standardized (as a whole) and then placed into one of the three criterion groups by sex. Using 1-standard-deviation increments (e.g., $-0.5<\mathrm{F}_{1} \leq 0.5$ ), the number of individuals with $\mathrm{F}_{1}$ scores within each interval was determined and plotted for each criterion group. The distributions of standardized scores for the three criterion groups, by sex, for each of the 10 DFAs appear in Figure 4. Members of the sciencemath criterion group are readily distinguished from members of the humanities or other criterion groups by their higher average $F_{1}$ scores. ${ }^{5}$ This pattern of results was replicated for both males and females across all five criterion variables and across both sets of analyses (viz., either the SOV or RIASEC teamed with spatial ability).

Clearly, the results in Phase 2 converge. The functions identify students with math-science promise, and again, over all analyses, spatial ability adds incremental validity beyond preferences for doing so. Spatial ability and preferences appear to coalesce among intellectually talented youth as they do in older students, and across all five criteria examined here, they appear to do so in functionally equivalent ways.
Phase 3: Incremental Validity of Spatial Ability Relative to Preferences and Mathematical and Verbal Abilities in Longitudinal Forecasts-Procedure and Results

Although measures of mathematical and verbal ability were not available for the full sample used in Phase 1 or the Phase 2 longitudinal sample, a subset of participants had been assessed on the SAT-M and SAT-V as well. Of the 547 participants for whom longitudinal data were available, 223 had taken the SAT. (Of the 513 participants without longitudinal data, 186 had taken the SAT; they constituted a replication sample.) Positive correlations were observed among the three ability measures: SAT-M and SAT-V, $r(403)=.50, p<.0001$; SAT-M and spatial ability, $r(420)=.24$, $p<.0001$; and SAT-V and spatial ability, $r(404)=.09, n s$.

A series of DFAs parallel to those in Phase 2 was based on the subset of participants with complete ability data: Again, five variables, each organized into the three groups (science-math, humani-

\footnotetext{
${ }^{5}$ For least favorite course, the abscissa has been reversed to reflect the nature of this variable-rather than representing a preference for something (as in favorite course, preferred leisure activities, major, and occupation), this variable reflects a dislike for something. Therefore, the second column of Figure 4 illustrates that participants with higher $F_{1}$ scores tended to report a math- or science-related course as their least favorite less frequently than did participants with lower $\mathrm{F}_{1}$ scores.
} 

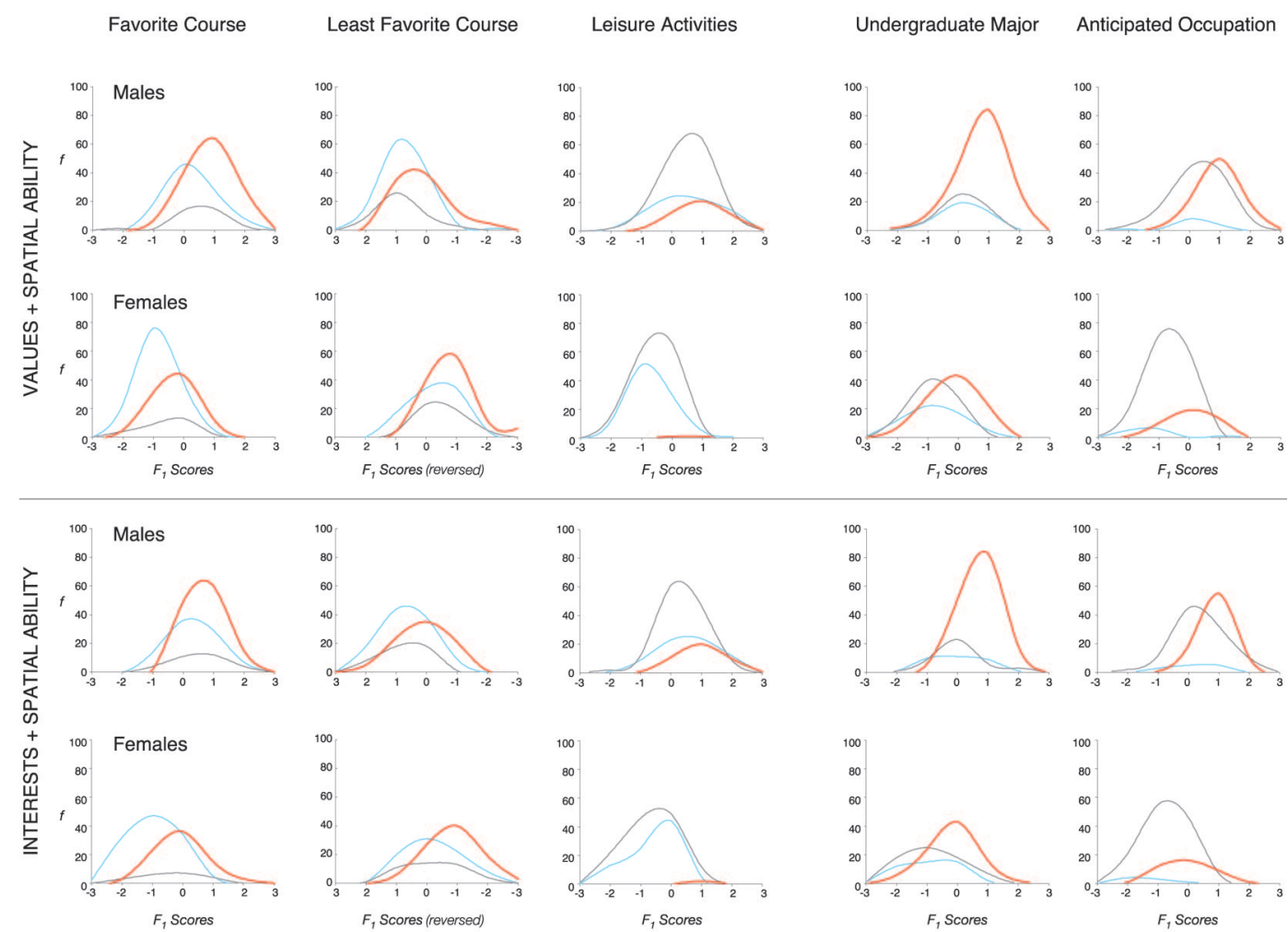

Humanities

Other

Science-math -

Figure 4. Distributions of scores for each criterion group, by sex, on first discriminant functions. Individuals were categorized according to their group membership (science-math, in red; humanities, in blue; or other, in gray) on each relevant criterion and graphed, by sex, according to their scores on each of the first discriminant functions. The top two rows represent functions based on values and spatial ability; the bottom two represent functions based on interests and spatial ability.

ties, or other), served as the criteria in two parallel series of DFAs: The first used values (SOV) and the three ability measures; the second included interests (RIASEC) and the three ability measures.

To test the hypothesis that spatial ability provides incremental validity over preferences and mathematical and verbal abilities in the prediction of group membership, we performed two series of three-step hierarchical DFAs. In the first five of these DFAs, the SOV was entered in the first step, mathematical and verbal ability in the second, and spatial ability in the third. Next, each of these analyses was repeated using RIASEC in the first step, mathematical and verbal abilities in the second, and spatial ability in the third. The incremental validity of spatial ability was assessed by examining the gain in the proportion of variance explained between the second and third steps. Summary information for each model appears in Table 4. Although there were insufficient sample sizes (159 to 211) for spatial ability to reach statistical significance across many of these analyses (especially given the number of variables entered before its evaluation), a clear pattern emerged. Averaged across all 10 analyses, spatial ability explained an additional $2.4 \%$ of the variance in group membership beyond that explained by preferences and verbal and mathematical abilities. These findings seem to suggest that spatial ability will enrich our understanding of intellectually precocious youth by adding value to the SAT and broad-spectrum preference inventories.

The same relationships hypothesized in Phase 2 were anticipated here, and we also hypothesized that mathematical ability would manifest a positive weight on the math-science function. A second function, defined largely by verbal ability and either aesthetic values (on the SOV) or artistic interests (on the RIASEC), was expected to discriminate members of the humanities groups from other participants. On examination of the structure matrices (see Table 5), it appeared that the first function $\left(\mathrm{F}_{1}\right)$ of each of the DFAs based on the SOV and abilities, regardless of criterion variable, consistently exhibited correlations with spatial (mean $r=$ .70) and mathematical (mean $r=.39$ ) abilities and theoretical (mean $r=.57$ ) and reversed social (mean $r=-.36$ ) values, as hypothesized. The first functions also exhibited consistent positive correlations with economic values (mean $r=.47$ ) and negative correlations with aesthetic values (mean $r=-.42$ ). Similarly, for DFAs based on RIASEC and abilities, $F_{1}$ exhibited consistent correlations with spatial (mean $r=.64$ ) and mathematical (mean $r=.30$ ) abilities and reversed social (mean $r=-.51$ ) interests for all criterion variables, as predicted, and consistent negative corre- 
Table 4

Incremental Validity of Spatial Ability Beyond Preferences, Verbal Ability, and Mathematical Ability in Discriminant Function Analyses (DFAs)

\begin{tabular}{|c|c|c|c|c|c|c|c|}
\hline Values + Abilities & Pillai's trace & $\Delta$ & $p$ & Interests + Abilities & Pillai's trace & $\Delta$ & $p$ \\
\hline Favorite course & & & & Favorite course & & & \\
\hline SOV & .11 & & & RIASEC & .16 & & \\
\hline $\mathrm{SOV}+\mathrm{M}+\mathrm{V}$ & .17 & .06 & .01 & RIASEC + M + V & .31 & .14 & .0001 \\
\hline $\mathrm{SOV}+\mathrm{M}+\mathrm{V}+\mathrm{S}$ & .18 & .01 & $n s$ & RIASEC $+M+V+S$ & .31 & .00 & ns \\
\hline Least favorite course & & & & Least favorite course & & & \\
\hline SOV & .06 & & & RIASEC & .11 & & \\
\hline $\mathrm{SOV}+\mathrm{M}+\mathrm{V}$ & .11 & .05 & .05 & RIASEC $+\mathrm{M}+\mathrm{V}$ & .19 & .08 & .001 \\
\hline $\mathrm{SOV}+\mathrm{M}+\mathrm{V}+\mathrm{S}$ & .15 & .04 & .05 & RIASEC $+\mathrm{M}+\mathrm{V}+\mathrm{S}$ & .22 & .03 & $n s$ \\
\hline Preferred leisure activity & & & & Preferred leisure activity & & & \\
\hline SOV & .08 & & & RIASEC & .13 & & \\
\hline $\mathrm{SOV}+\mathrm{M}+\mathrm{V}$ & .15 & .07 & .01 & RIASEC + M + V & .18 & .05 & .01 \\
\hline $\mathrm{SOV}+\mathrm{M}+\mathrm{V}+\mathrm{S}$ & .17 & .02 & $n s$ & RIASEC $+M+V+S$ & .19 & .01 & $n s$ \\
\hline Undergraduate major & & & & Undergraduate major & & & \\
\hline SOV & .20 & & & RIASEC & .26 & & \\
\hline $\mathrm{SOV}+\mathrm{M}+\mathrm{V}$ & .31 & .11 & .0001 & RIASEC + M + V & .39 & .13 & .0001 \\
\hline $\mathrm{SOV}+\mathrm{M}+\mathrm{V}+\mathrm{S}$ & .34 & .03 & .05 & RIASEC $+\mathrm{M}+\mathrm{V}+\mathrm{S}$ & .41 & .02 & ns \\
\hline Anticipated occupation & & & & Anticipated occupation & & & \\
\hline SOV & .15 & & & RIASEC & .15 & & \\
\hline $\mathrm{SOV}+\mathrm{M}+\mathrm{V}$ & .19 & .04 & .05 & RIASEC + M + V & .16 & .01 & $n s$ \\
\hline $\mathrm{SOV}+\mathrm{M}+\mathrm{V}+\mathrm{S}$ & .23 & .04 & .05 & RIASEC $+M+V+S$ & .20 & .04 & .05 \\
\hline
\end{tabular}

Note. The first row of each set of three rows reports the Pillai's trace statistic (explained variance) for the DFA based on preferences alone; the second reports Pillai's trace for DFA based on preferences and mathematical and verbal abilities, the incremental validity of the second model $(\Delta)$, and the $p$ value of the significance test for additional variance explained; the third reports Pillai's trace for DFA based on preferences and mathematical, verbal, and spatial abilities; the incremental validity of the third model over the second $(\Delta)$; and the $p$ value of the significance test for additional variance explained. Values of delta may not equal the differences between reported Pillai's trace statistics due to rounding. SOV = Study of Values; RIASEC $=$ general occupational themes of the Strong Interest Inventory; $\mathrm{M}=$ mathematical ability; $\mathrm{V}=$ verbal ability; $\mathrm{S}=$ spatial ability.

lations with artistic (mean $r=-.69$ ) and enterprising (mean $r=$ -.42 ) interests. No pattern was clear for $\mathrm{F}_{2}$.

As in Phase 2, the stability of the first functions across these analyses may be more fully appreciated by correlating participants' scores on these functions. Scores on each discriminant function were calculated for the 223 talent search participants with SAT scores for whom longitudinal data were available and, for replication purposes, the 186 participants with SAT scores for whom longitudinal data were not available. The intercorrelations among function scores (across the five different analyses of each set) were again consistently high (see Appendix B, Table B1). The average intercorrelation among the first functions based on values and abilities was $.82(S D=.08)$ for participants with longitudinal data, and this replicated in participants without longitudinal data, averaging $.83(S D=.08)$. The average intercorrelation among the first functions based on interests and abilities was $.80(S D=.07)$ for the subsample with longitudinal data and $.78(S D=.07)$ for participants without such data. Across-instrument correlations among participants' $\mathrm{F}_{1}$ scores averaged $.71(S D=.08)$ among participants with longitudinal data and $.70(S D=.08)$ among participants without (see Appendix B, Table B2). Once again, the first functions appeared to draw on the same constellation of constructs running through each predictor set, regardless of the external criterion or preference instrument used.

To illustrate the psychological space that these groups occupy along these discriminant functions, participants' scores from each function were standardized, and subsequently participants were categorized into the three criterion groups. Because Phase 3 was more exploratory in nature, each group's standing on both functions is presented in each of the 10 coordinate systems presented in Figure 5.

Across all 10 analyses (combined across sex due to the small sample sizes), members of the science-math criterion group exhibited higher scores on the first discriminant functions than members of the humanities or other criterion groups and are readily distinguished from them by their location to the right of the other two criterion groups. The math-science group appeared to occupy a different psychological location than the other two groups in the space defined by these two discriminant functions. The math-science group is readily isolated from the other two as a function of its high standing on $F_{1}$, illustrating, again, the potential of $F_{1}$ to identify students at promise for developing math-science expertise.

\section{Discussion}

This study investigated the psychological importance of spatial ability among intellectually talented adolescents, with a particular emphasis on predicting outcomes along the math-science pipeline. Findings support the conclusion that spatial ability plays a role in predicting STEM-related pursuits. By not assessing youth along this dimension, we may be missing many who have the potential to pursue STEM careers, which is of such importance to U.S. competitiveness (Friedman, 2005). Those who possess high spatial ability display an ability-preference fit with pursuing STEM careers. Moreover, spatial ability appears to provide unique information beyond preferences and other cognitive abilities (viz., quantitative and verbal) in understanding STEM-related achieve- 
Table 5

Two Sets of Discriminant Functions (Values + Abilities and Interests + Abilities) for Five Criterion Variables Across Three Criterion Groups (Science-Math, Humanities, Other)

\begin{tabular}{|c|c|c|c|c|c|c|c|c|c|c|c|}
\hline \multirow[b]{2}{*}{ Dimension } & \multicolumn{5}{|c|}{$\mathrm{F}_{1}$} & \multirow[b]{2}{*}{$M$} & \multicolumn{5}{|c|}{$\mathrm{F}_{2}$} \\
\hline & Fav. & Least & Leis. & Major & Occ. & & Fav. & Least & Leis. & Major & Occ. \\
\hline \multicolumn{12}{|c|}{ Values + Abilities } \\
\hline Theoretical & .57 & .45 & .55 & .63 & .66 & .57 & .29 & .40 & .38 & .23 & .19 \\
\hline Economic & .52 & .33 & .59 & .49 & .42 & .47 & .00 & .49 & -.26 & -.29 & .64 \\
\hline Aesthetic & -.39 & -.21 & -.51 & -.48 & -.51 & -.42 & .81 & -.44 & -.02 & .62 & -.13 \\
\hline Social & -.36 & -.22 & -.54 & -.30 & -.37 & -.36 & -.16 & -.32 & -.32 & .05 & -.61 \\
\hline Religious & -.32 & -.13 & -.30 & -.04 & -.07 & -.17 & -.52 & -.28 & .39 & -.18 & -.30 \\
\hline Verbal ability & -.35 & .01 & -.40 & .00 & -.19 & -.19 & .25 & .49 & .62 & .64 & .19 \\
\hline Math ability & .46 & .59 & .17 & .39 & .32 & .39 & .13 & -.18 & .42 & .07 & -.37 \\
\hline Spatial ability & .58 & .84 & .70 & .64 & .74 & .70 & .30 & .27 & .41 & .30 & .24 \\
\hline Pillai's trace & .16 & .13 & .14 & .24 & .21 & & .03 & .03 & .03 & .10 & .02 \\
\hline
\end{tabular}

Interests + Abilities

\begin{tabular}{|c|c|c|c|c|c|c|c|c|c|c|c|}
\hline Realistic & .06 & .22 & -.13 & .20 & .22 & .11 & -.27 & .10 & -.58 & -.50 & -.05 \\
\hline Investigative & .00 & .01 & -.40 & .30 & .05 & -.04 & .11 & .37 & -.57 & -.35 & -.34 \\
\hline Artistic & -.61 & -.50 & -.81 & -.65 & -.58 & -.69 & .48 & .32 & .07 & -.43 & -.27 \\
\hline Social & -.51 & -.42 & -.76 & -.29 & -.58 & -.51 & -.20 & .56 & -.26 & .10 & .31 \\
\hline Enterprising & -.52 & -.39 & -.55 & -.34 & -.32 & -.42 & -.54 & .46 & -.26 & .13 & .00 \\
\hline Conventional & .02 & .23 & -.35 & .14 & .06 & .02 & -.32 & .50 & -.24 & .00 & -.28 \\
\hline Verbal ability & -.44 & .03 & -.33 & -.17 & -.28 & -.24 & .25 & -.45 & .54 & -.61 & -.37 \\
\hline Math ability & .30 & .40 & .22 & .31 & .29 & .30 & .09 & .40 & .07 & -.32 & .17 \\
\hline Spatial ability & .47 & .68 & .66 & .55 & .82 & .64 & -.03 & -.03 & -.08 & -.41 & -.02 \\
\hline Pillai's trace & .22 & .18 & .16 & .28 & .19 & & .09 & .04 & .04 & .13 & .01 \\
\hline
\end{tabular}

Note. Correlations reflect the structure matrices of discriminant function analyses based on each preference dimension and three ability measures in each of five discriminant functions based on a preference measure (either SOV or RIASEC) and three ability measures with favorite course (Fav.), least favorite course (Least), preferred leisure activity (Leis.), undergraduate major (Major), and expected occupation (Occ.) as the criterion variables. The proportion of variance in group membership (science-math, humanities, or other) that is explained by each function (Pillai's trace) is reported for each function. The column of means $(M)$ represents the means of the preceding five correlations. $\mathrm{F}_{1}=$ first discriminant function; $\mathrm{F}_{2}=$ second discriminant function.

ment. These findings, when combined with others (Gohm et al., 1998; Humphreys et al., 1993; Humphreys \& Lubinski, 1996; Shea et al., 2001), suggest that by incorporating spatial ability into talent identification procedures (Eliot, 1987), educators and counselors are not only likely to identify an underserved population of students - those who are particularly gifted in nonverbal ideationbut also a valuable source of human capital for STEM. Indeed, one does not measure nonverbal ideation very well unless one measures spatial visualization abilities (Lohman, 1994, 2005).

Spatially talented students are currently missed by modern talent search programs unless they happen to be mathematically or verbally gifted (recall that more than half of the top $1 \%$ in spatial ability are missed when talent searches rely on traditional math and verbal measures; Lohman \& Korb, 2006; Shea et al., 2001 [see footnote 1]). This study demonstrates that an appreciable number of adolescents who might be identified by their extreme standing on spatial ability, if it were incorporated into talent search methods, would have interests in STEM pursuits. Of course, it is not reasonable to expect all adolescents with high spatial ability to become world-class leaders in STEM, but many of them do appear to have the requisite abilities and preferences to become competent professionals in STEM careers, if they so choose. Moreover, it is quite possible that some adolescents in the 90th to 98th percentile range of mathematical ability (who are, therefore, missed by current methods) who are truly extraordinary in spatial ability possibly could make notable creative contributions to STEM areas. Although it is not well known, Lewis Terman rejected two Nobel Laureates in physics, Luis Alverez and William Shockley, for his famous longitudinal study of intellectual talent by restricting selection to the highly verbal Stanford-Binet (Shurkin, 1992). Although modern talent searches are probably not losing many students with the potential of Alverez or Shockley, due to the assessment of mathematical reasoning ability, we may be losing many modern-day Thomas Edisons and Henry Fords by not assessing and selecting for students gifted in spatial visualization.

The sample analyzed here afforded a rare opportunity to examine how spatially talented young adolescents look psychologically in terms of their interests, values, and educational-occupational inclinations and, simultaneously, how intellectually talented students who score relatively low on spatial ability fare on these dimensions. Spatially talented students, relative to other intellectually able students with less remarkable spatial skills, tended to exhibit strong theoretical values and prominent mathematical, mechanical, and scientific interests, similar to the interest and value profiles of math-science graduate students and STEM professionals. Moreover, the high-space adolescents in this study shared low 


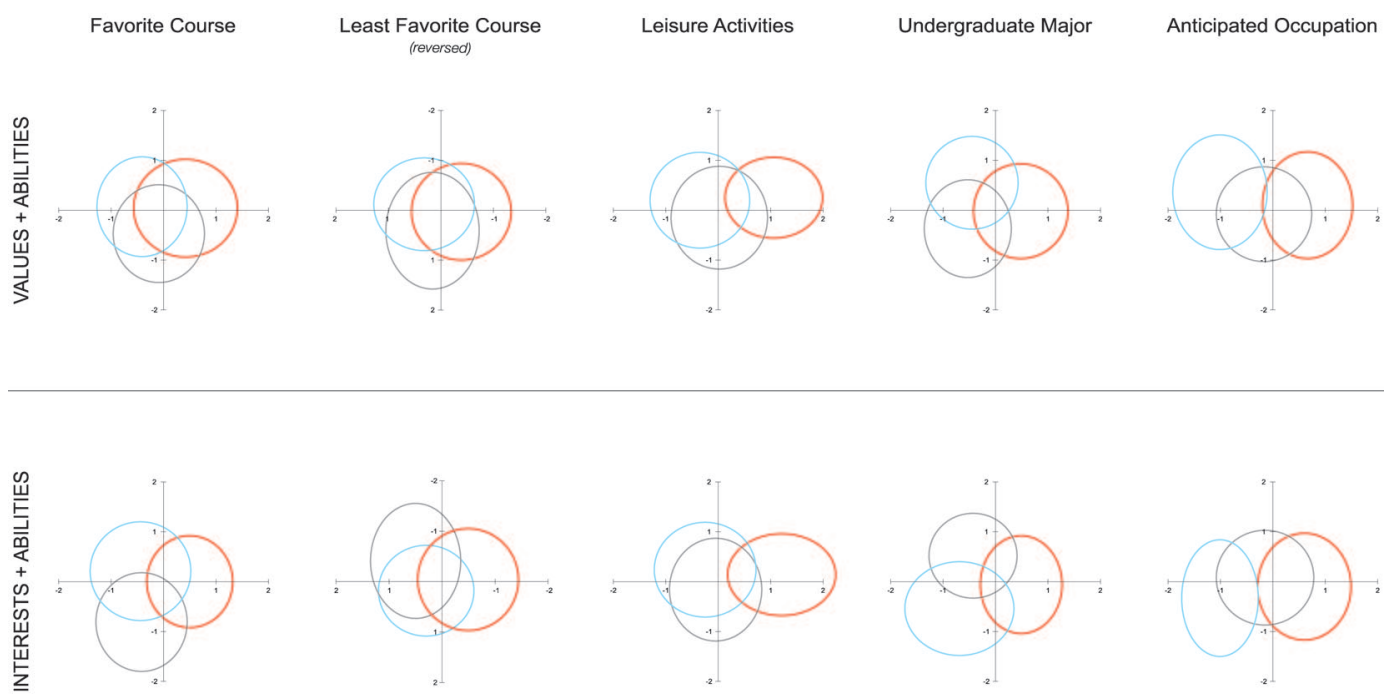

Humanities $\quad$ Other - Science-math -

Figure 5. Scores on discriminant functions for each criterion group. Individuals were categorized according to their group membership (science-math, humanities, or other) on each relevant criterion variable and graphed according to their scores on each of the discriminant functions. The top row represents functions based on values and abilities; the bottom row represents functions based on interests and abilities. In each coordinate system, the $x$ axis represents scores on the first functions $\left(F_{1}\right)$, and the $y$ axis represents scores on the second functions $\left(\mathrm{F}_{2}\right)$. Each ellipse represents science-math (in red), humanities (in blue), or other (in gray) and is centered at the bivariate mean of the $F_{1}$ and $F_{2}$ scores for each criterion group. Each ellipse originates at the mean scores on $F_{1}$ and $\mathrm{F}_{2}$ (as $x, y$ coordinates) for each of the three criterion groups. The shape of the ellipse is defined by the standard deviations of the function scores for that group; that is, the ellipse is extended from its origin horizontally 1 standard deviation of the $F_{1}$ scores of the group to the left and 1 standard deviation to the right. The ellipse is extended from its origin vertically 1 standard deviation of the $\mathrm{F}_{2}$ scores of that group up and 1 standard deviation down. These isodensity ellipses estimate where approximately $68 \%$ ( \pm 1 SD) of the group is located.

standing with math-science graduate students on several preference dimensions, including political and religious values and enterprising and conventional interests, underscoring an underappreciated point: Relative weaknesses and dislikes can be as important to consider in educational-vocational counseling as relative strengths and preferences (Achter, Lubinski, \& Benbow, 1996; Benbow \& Lubinski, 1996; Dawis, 1992, 2001; Harmon, 1989; Lubinski \& Benbow, 2000, 2006; R. E. Snow et al., 1996; Tyler, 1974; Williamson, 1965). Although the latter clearly influence the educational-vocational niches that people self-select into (approach), the niches that people select out of (avoid) are influenced by the former (Gottfredson, 2003; Lubinski, 2004; Scarr, 1996; Scarr \& McCartney, 1983).

When overall profile similarity was evaluated, by sex, using math-science graduate students as a criterion reference, female adolescents with high spatial ability were more congruent with their same-sex graduate student counterparts than were female adolescents with relatively low levels of spatial ability, which solidify the above conclusions for females. The profile analyses for the males were all in the predicted direction but did not reach statistical significance. As an anonymous reviewer pointed out, this suggests that spatial ability may be more relevant for identifying math-science promise in girls relative to boys (for further support of this idea, see Shea et al., 2001, Figure 2).

Longitudinal analyses of the incremental validity of spatial ability over preferences across favorite and least favorite high school courses, leisure interests, undergraduate major, and intended occupation revealed consistent findings. Spatial ability exhibited incremental validity above the SOV and RIASEC themes in predicting these criteria; moreover, in each analysis, the first discriminant function appeared to capture potential for developing math-science expertise. Density curves for each sex (Figure 4) highlight the separation of the science-math group from the other two groups (humanities and other) on this function in standard deviation (or effect size) units. An analysis of the covariance structure of these functions, which replicated in an independent sample, supported the following conclusion: Psychologically, interests and values appear to team with spatial ability in functionally equivalent ways - combining competency and preference attributes - to isolate students with affinities for math-science. Just as the construct validity of measures is appraised by the convergent and discriminant patterns they display within a nomological 
network (Campbell \& Fiske, 1959; Cronbach \& Meehl, 1955; Embretson, 1983), Figures 4 and 5 reflect a convergentdiscriminant patterning formed by functionally equivalent indicators across multiple developmentally sequenced longitudinal criteria. To the extent that students possess high standings on these aptitude complexes (Lohman, 1988, 1994, 2005; R. E. Snow \& Lohman, 1989) or trait clusters (Ackerman, 1996; Ackerman \& Heggestad, 1997), they are likely equipped with both the passion to persevere and the competencies to meet the challenges as math-science learning and working environments become more demanding.

To our knowledge, the incremental validity of spatial ability has never been assessed relative to the SAT in conjunction with a broad-spectrum preference instrument in a conventional talent search population. Phase 3 examined the value-added contribution of spatial ability relative to the SAT and two well-known preference instruments independently. As hypothesized, spatial ability exhibited incremental validity over both the SAT + RIASEC and the SAT + SOV; the magnitude of this increment averaged $2.4 \%$ over the 10 sets of analyses in Phase 3. However, because the number of variables controlled for before evaluating the incremental validity of spatial ability was atypically stringent and the sample sizes were relatively small (ranging from 159 to 211), only 4 of the 10 statistical tests achieved statistical significance. Nevertheless, the uniformity found in the discriminant function structure matrices suggests that more stable and statistically significant contributions of spatial ability beyond the SAT + preferences may be secured in subsequent studies using larger samples. Moreover, the series of ellipses in Figure 5, scaled in effect-size units, reveals a consistent separation of the math-science group from the other two groups. Given the isomorphism of the intercorrelations across the discriminant functions, which replicated in an independent sample, and the clarity and consistency of the ellipses derived from them, Meehl's $(1978,1990)$ perspective is important to underscore in interpreting these results: In the early stages of testing psychological theories, consistency in function form is more germane than statistical significance. We are clearly in the early stages of theory testing here.

Of course, the specific abilities examined share an appreciable general factor $(g)$, which is true of all abilities just below the vertex of Carroll's (1993) hierarchy or just off center from the centroid of Snow's radex (R. E. Snow \& Lohman, 1989). However, the intercorrelations among the ability measures reported here were substantially lower than those observed in more normative populations (cf. Carroll, 1993; Humphreys et al., 1993: math-verbal, $r \approx .80$; math-spatial, $r \approx .60$; and verbal-spatial, $r \approx .60$ ). Yet, across all five discriminant functions, for both the RIASEC and the SOV (see Table 5), there was a consistent tendency for verbal ability to be negatively correlated with $\mathrm{F}_{1}$. For the analyses based on Values + Abilities, the average correlation was -.19; for Interests + Abilities, the average correlation was - .24. In contrast, there was a tendency for mathematical and spatial ability to be positively correlated with $\mathrm{F}_{1}$. Average correlations between SAT-M and $\mathrm{F}_{1}$ were .39 (for Values + Abilities) and .30 (for Interests + Abilities), and average correlations between spatial ability and $\mathrm{F}_{1}$ were .70 (for Values + Abilities) and .64 (for Interests + Abilities).
These results were consistent with research using other samples. It has been shown that, when intellectually talented students are appreciably more verbally than mathematically talented, their verbal gifts tend to propel them toward areas outside the math-science pipeline (Humphreys et al., 1993; Lubinski, Benbow, et al., 2001; Lubinski, Webb, et al., 2001; Shea et al., 2001). The discriminant functions in Phase 3 appear to capture these differential inclinations emanating from differences in specific ability profiles. ${ }^{6}$ It is important to stress, however, that these patterns should not be interpreted as though verbal ability is unimportant for scientific pursuits. Rather, it would be more precise to say that to the extent that intellectually talented students possess verbal abilities relatively higher than their mathematical and spatial abilities, they tend to be more attracted to developing their talents in intellectually demanding areas outside of STEM (Lubinski, Benbow, et al., 2001; Lubinski, Webb, et al., 2001; Park et al., in press; Shea et al., 2001; Webb, Lubinski, \& Benbow, 2002). This is one of the reasons R. E. Snow (1994; R. E. Snow et al., 1996) has proposed that the concept of aptitude be broadened to encompass individual differences in both cognitive and motivational constructs.

Overall, given the consistencies in profile similarity, predictive validity, and covariance structure (complete with a two-tiered generalization probe, which replicated) and coupled with the ways in which our findings align with preexisting studies (Gohm et al., 1998; Humphreys \& Lubinski, 1996; Humphreys et al., 1993; Shea et al., 2001), our findings suggest how we can possibly refine and expand the identification of students with potential for STEM-related careers ${ }^{7}$ and, thus, enlarge the pool of identified talent.

However, limitations in this study suggest that more research is needed. For example, our replication of the psychological equivalencies running through our discriminant functions constituted a literal replication in Lykken's (1968) three-tiered formulation of replications in psychological research: literal, operational, and constructive. The latter two are more scientifically compelling. Future research should aim to replicate the findings observed here by using other measures of similar constructs and other criteria that are just as meaningful as those

\footnotetext{
${ }^{6}$ That the intercorrelations of these discriminant functions are uniformly high illustrates that the same underlying constructs are operating in functionally equivalent ways across these educational-occupational criteria. Intercorrelation matrices both within and between RIASEC and the SOV (including a replication using the Time 1 participants without Time 2 data) constitute a revealing methodological and substantive demonstration of how the constituent variables function in aggregate: Variations in discriminative function weights assigned to each variable nevertheless aggregate to form functionally equivalent variates. Just as beta weights bounce in multiple regression due to multicollinearity among predictors, discriminant function weights exchange roles in accounting for redundant variance in the same way. Each discriminant function could be used to generate comparable and meaningful results across the remaining four criterion variables.

${ }^{7}$ Counselors and educators may eventually be able to identify potential for the math-science pipeline by assessing individual differences on these functions. One feature to keep in mind when using discriminant functions to advise individual students is that the variables used are allowed to operate in a compensatory fashion. For further and more detailed reading on making inferences about individuals on the basis of aggregated individual differences data, readers are referred to Dawis (1996) and Grove and Meehl (1996).
} 
assembled here. With respect to the latter, although spatial ability appears to be relevant to math-science pursuits, preexisting literature suggests other pursuits as well, for example, architecture and many of the creative arts (Gardner, 1993; Humphreys et al., 1993). Therefore, investigators should be encouraged to consider examining the importance of spatial ability in educational and career arenas beyond STEM.

\section{Broader Considerations}

These findings may be viewed in light of what we already know about the kinds of environments to which older spatially talented individuals are drawn and their educational success. Older spatially talented individuals have been drawn to environments that involve working with technology and manipulating things (Humphreys \& Lubinski, 1996; Humphreys et al., 1993). Although these interests are indeed conducive to development in many technical and trade fields, as spatially able students have been steered in the past, they are not limited to these fields (Smith, 1964). These interests are also relevant to high-level development in scientific and engineering domains (Gottfredson, 1986, 2002; Silverman, 1998; Xie \& Shauman, 2003). However, because spatially talented youth are at a higher risk for academic underachievement than other gifted youth, they are more likely to become occupationally underemployed (Gohm et al., 1998). For example, an examination of the top $1 \%$ of spatial talent and the top $1 \%$ of mathematical talent selected from a stratified random sample of approximately 100,000 high school seniors revealed that spatially gifted students exhibited much lower educational aspirations and achievements than mathematically gifted students. Approximately three times as many high-space students, relative to high-math students, secured no educational degree beyond high school, and, conversely, fewer than half as many high-space students, relative to mathematically talented students, secured graduate degrees. Furthermore, spatially talented students reported less motivation to perform in school than high-math students on a variety of indicators, including attention in class, enjoyment of assignments, and actual time spent studying (Gohm et al., 1998).

Following R. E. Snow et al. (1996), an aptitude complex or ability-preference approach suggests explanations for the underachievement of spatially talented students relative to students gifted in other content domains (e.g., mathematics; Gohm et al., 1998). Spatially talented students may be dissuaded from pursuing postsecondary education because of the strong verbal and mathematical orientation of current K-12 curricula (Silverman, 1998). They might be better served by a curriculum that relies more on reasoning with figures and shapes, their preferred medium of ideation but not often offered as part of school curriculum, and less on words and numbers, the media typically preferred by verbally and mathematically talented students and provided by schools. Just as mathematically or verbally gifted students learn best in environments designed with their particular strengths and preferences in mind (Colangelo et al., 2004; Colangelo \& Davis, 2003; VanTassel-Baska, 1998), spatially talented students stand to benefit from educational programming tailored to the unique features of their individuality (Lohman, 1988, 1994, 2005; R. E. Snow \& Lohman, 1989).
Unfortunately, such educational experiences are missing in today's schools. If we identify spatially talented students and modify their curriculum to more fully engage them in the educational process by capitalizing on their intellectual strengths and personal preferences (e.g., developing courses in robotics, increased lab work in science classes, or, perhaps, the option of reading biographies of scientists and inventors in literature classes), could this increase their motivation and commitment to their own educational development?

\section{Conclusion}

In the words of Corno et al. (2002), "If spatial-mechanical reasoning. . is a component of achievement in some walks of science, then educators and program evaluators should be giving it direct attention" (p. 73). Adding spatial ability to talent identification procedures, in which more than 300,000 U.S. students participate annually, would give it such direct attention. Doing so would enable the identification of adolescents at promise for developing math-science expertise who are currently overlooked and, more generally, facilitate an appreciation of how spatial ability can refine educational placement, programming, and the developmental modeling of all intellectually talented youth.

\section{References}

Achter, J. A., \& Lubinski, D. (2003). Fostering exceptional development in intellectually talented populations. In W. B. Walsh (Ed.), Counseling psychology and optimal human functioning (pp. 25-54). Mahwah, NJ: Erlbaum.

Achter, J. A., \& Lubinski, D. (2005). Blending promise with passion: Best practices for counseling intellectually talented youth. In S. D. Brown \& R. W. Lent (Eds.), Career development and counseling: Putting theory and research to work (pp. 600-624). Hoboken, NJ: Wiley.

Achter, J. A., Lubinski, D., \& Benbow, C. P. (1996). Multipotentiality among the intellectually gifted: "It was never there and already it's vanishing." Journal of Counseling Psychology, 43, 65-76.

Achter, J. A., Lubinski, D., Benbow, C. P., \& Eftekhari-Sanjani, H. (1999). Assessing vocational preferences among gifted adolescents adds incremental validity to abilities: A discriminant analysis of educational outcomes over a 10-year interval. Journal of Educational Psychology, 91, $777-786$.

Ackerman, P. L. (1996). A theory of adult intellectual development: Process, personality, interests, and knowledge. Intelligence, 22, 227 257.

Ackerman, P. L., \& Heggestad, E. D. (1997). Intelligence, personality, and interests: Evidence for overlapping traits. Psychological Bulletin, 121, $218-245$

Allport, G. W., Vernon, P. E., \& Lindzey, G. (1970). Manual: Study of Values. Boston: Houghton Mifflin.

Armstrong, P. I., Smith, T. J., Donnay, D. A. C., \& Rounds, J. (2004). The Strong ring: A basic interest model of occupational structure. Journal of Counseling Psychology, 51, 299-313.

Austin, J. T., \& Hanisch, K. A. (1990). Occupational attainment as a function of abilities and interests: A longitudinal analysis using Project Talent data. Journal of Applied Psychology, 75, 77-86.

Barnett, L. B., \& Gilheany, S. (1996). The CTY talent search: International applicability and practice in Ireland. High Ability Studies, 7, 179-190.

Benbow, C. P. (1988). Sex differences in mathematical reasoning ability 
among the intellectually talented: Their characterization, consequences, and possible causes. Behavioral and Brain Sciences, 11, 169-232.

Benbow, C. P. (1992). Academic achievement in mathematics and science of students between ages 13 and 23: Are there differences among students in the top one percent of mathematical ability? Journal of Educational Psychology, 84, 51-61.

Benbow, C. P., \& Lubinski, D. (1996). Intellectual talent: Psychometric and social issues. Baltimore: Johns Hopkins University Press.

Benbow, C. P., Lubinski, D., Shea, D. L., \& Eftekhari-Sanjani, H. (2000). Sex differences in mathematical reasoning ability: Their status 20 years later. Psychological Science, 11, 474-480.

Benbow, C. P., \& Stanley, J. C. (1996). Inequity in equity: How "equity" can lead to inequity for high-potential students. Psychology, Public Policy, and Law, 2, 249-292.

Benbow, C. P., \& Wolins, L. (1996). The utility of out-of-level testing for gifted seventh and eighth graders using the SAT-M: An examination of item bias. In C. P. Benbow \& D. Lubinski (Eds.), Intellectual talent: Psychometric and social issues (pp. 333-346). Baltimore: Johns Hopkins University Press.

Bennett, G. K. (1969). Bennett Mechanical Comprehension Test: Forms S and T (test manual). New York: Psychological Corporation.

Betz, N. E. (1987). Use of discriminant analysis in counseling psychology research. Journal of Counseling Psychology, 34, 393-403.

Bleske-Rechek, A., Lubinski, D., \& Benbow, C. P. (2004). Meeting the educational needs of special populations: Advanced Placement's role in developing exceptional human capital. Psychological Science, 15, 217224.

Bose, R. C., \& Roy, S. N. (1938). The distribution of the studentised $\mathrm{D}^{2}$-statistic. Sankhya: The Indian Journal of Statistics, 4, 19-38.

Brody, L. E., \& Benbow, C. P. (1990). Effects of high school coursework and time on SAT scores. Journal of Educational Psychology, 82, 866875.

Brown, S. D., \& Gore, P. A., Jr. (1994). An evaluation of interest congruence indices: Distributional characteristics and measurement properties. Journal of Vocational Behavior, 45, 310-327.

Cacoullos, T. (1962). Comparing Mahalanobis distances. Unpublished doctoral dissertation, Columbia University.

Campbell, D. T., \& Fiske, D. W. (1959). Convergent and discriminant validation by the multitrait-multimethod matrix. Psychological Bulletin, $56,81-105$.

Carroll, J. B. (1993). Human cognitive abilities: A survey of factor-analytic studies. Cambridge, UK: Cambridge University Press.

Cattell, R. B. (1957). Personality and motivation structure and measurement. Yonkers, NY: World Book.

Colangelo, N., Assouline, S. G., \& Gross, M. U. M. (Eds.). (2004). A nation deceived: How schools hold back America's brightest students. Iowa City: University of Iowa.

Colangelo, N., \& Davis, G. A. (Eds.). (2003). Handbook of gifted education (3rd ed.). New York: Allyn \& Bacon.

Corno, L., Cronbach, L. J., Kupermintz, H., Lohman, D. F., Mandinach, D., Porteus, A. W., et al. (2002). Remaking the concept of aptitude: Extending the legacy of Richard E. Snow. Mahwah, NJ: Erlbaum.

Cronbach, L. J., \& Gleser, G. C. (1953). Assessing similarities between profiles. Psychological Bulletin, 50, 456-473.

Cronbach, L. J., \& Meehl, P. E. (1955). Construct validity in psychological tests. Psychological Bulletin, 52, 281-302.

Dawes, R. M. (1979). The robust beauty of improper linear models in decision making. American Psychologist, 34, 571-582.

Dawes, R. M., \& Corrigan, B. (1974). Linear models in decision making. Psychological Bulletin, 81, 95-106.

Dawis, R. V. (1991). Vocational interests, values, and preferences. In M. D. Dunnette \& L. M. Hough (Eds.), Handbook of industrial and organizational psychology (Vol. 2, pp. 833-871). Palo Alto, CA: Consulting Psychologist Press.

Dawis, R. V. (1992). The individual differences tradition in counseling psychology. Journal of Counseling Psychology, 39, 7-19.

Dawis, R. V. (1996). Vocational psychology, vocational adjustment, and the workforce: Some familiar and unanticipated consequences. Psychology, Public Policy, and Law, 2, 229-248.

Dawis, R. V. (2001). Toward a psychology of values. The Counseling Psychologist, 29, 458-465.

Dawis, R. V., \& Lofquist, L. H. (1984). A psychological theory of work adjustment: An individual differences model and its applications. Minneapolis: University of Minnesota Press.

Day, S. X., \& Rounds, J. (1998). The universality of vocational interest structure among racial and ethnic minorities. American Psychologist, 53, $728-736$.

Day, S. X., Rounds, J., \& Swaney, K. (1998). The structure of vocational interests for diverse racial-ethnic groups. Psychological Science, 9, $40-44$.

Eliot, J. (1987). Models of psychological space: Psychometric, developmental, and experimental approaches. New York: Springer-Verlag.

Embretson, S. E. (1983). Construct validity: Construct representation versus nomothetic span. Psychological Bulletin, 93, 179-197.

Flanagan, J. C., Dailey, J. T., Shaycoft, M. F., Gorman, W. A., Orr, D. B., \& Goldberg, I. (1962). Design for a study of American youth. Boston: Houghton Mifflin.

Friedman, T. L. (2005). The world is flat: A brief history of the twenty-first century. New York: Farrar, Straus \& Giroux.

Gallagher, J., \& Gallagher, S. (1994). Teaching the gifted child (4th ed.). Boston: Allyn \& Bacon.

Gardner, H. (1993). Frames of mind. New York: Basic Books.

Geary, D. C. (1998). Male, female: The evolution of human sex differences. Washington, DC: American Psychological Association.

Geary, D. C. (2004). The origin of mind: Evolution of brain, cognition, and general intelligence. Washington, DC: American Psychological Association.

Gohm, C. L., Humphreys, L. G., \& Yao, G. (1998). Underachievement among spatially gifted students. American Educational Research Journal, 35, 515-531.

Gorsuch, R. L. (1983). Factor analysis (2nd ed.). Hillsdale, NJ: Erlbaum.

Gottfredson, L. S. (1986). Occupational aptitude patterns map: Development and implications for a theory of job aptitude requirements [Monograph]. Journal of Vocational Behavior, 29, 254-291.

Gottfredson, L. S. (2002). Assess and assist individuals, not sexes. Issues in Education, 8, 39-47.

Gottfredson, L. S. (2003). The challenge and promise of cognitive career assessment. Journal of Career Assessment, 11, 115-135.

Grove, W. M., \& Meehl, P. E. (1996). Comparative efficiency of formal (mechanical, algorithmic) and informal (subjective, impressionistic) prediction procedures: The clinical/statistical controversy. Psychology, Public Policy, and Law, 2, 293-323.

Halpern, D. F. (2000). Sex differences in cognitive abilities (3rd ed.). Mahwah, NJ: Erlbaum.

Hansen, J. C., \& Campbell, D. P. (1985). Manual for the SVIB-SCII. Palo Alto, CA: Consulting Psychologists Press.

Harmon, L. W. (1989). Counseling. In R. L. Linn (Ed.), Educational measurement (3rd ed., pp. 527-543). New York: Collier.

Hedges, L. V., \& Nowell, A. (1995, July 7). Sex differences in mental test scores, variability, and numbers of high-scoring individuals. Science, 269, 41-45.

Heller, K. A., Monks, F. J., Sternberg, R. J., \& Subotnik, R. F. (Eds.). (2000). International handbook of giftedness and talent. New York: Elsevier. 
Holland, J. L. (1996). Exploring careers with a typology. American Psychologist, 51, 397-406.

Holland, J. L. (1997). Making vocational choices: A theory of vocational personalities and work environments (3rd ed.). Odessa, FL: Psychological Assessment Resources.

Humphreys, L. G., \& Lubinski, D. (1996). Brief history and psychological significance of assessing spatial visualization. In C. P. Benbow \& D. Lubinski (Eds.), Intellectual talent: Psychometric and social issues (pp. 116-140). Baltimore: Johns Hopkins University Press.

Humphreys, L. G., Lubinski, D., \& Yao, G. (1993). Utility of predicting group membership and the role of spatial visualization in becoming an engineer, physical scientist, or artist. Journal of Applied Psychology, 78, $250-261$.

Keating, D. P., \& Stanley, J. S. (1972). Extreme measures for the mathematically gifted in mathematics and science. Educational Researcher, 1, $3-7$.

Kimura, D. (1999). Sex and cognition. Cambridge, MA: MIT Press.

Kopelman, R. E., Rovenpor, J. L., \& Guan, M. (2003). The Study of Values: Construction of the fourth edition. Journal of Vocational Behavior, 62, 203-220.

Kuse, A. R. (1977). Familial resemblances for cognitive abilities estimated from two test batteries in Hawaii. Unpublished doctoral dissertation, University of Colorado, Boulder.

Lofquist, L. H., \& Dawis, R. V. (1991). Essentials of person environment correspondence counseling. Minneapolis: University of Minnesota Press.

Lohman, D. F. (1988). Spatial abilities as traits, processes, and knowledge. In R. J. Sternberg (Ed.), Advances in the psychology of human intelligence (Vol. 4, pp. 181-248). Hillsdale, NJ: Erlbaum.

Lohman, D. F. (1994). Spatially gifted, verbally inconvenienced. In N. Colangelo, S. G. Assouline, \& D. L. Ambroson (Eds.), Talent development: Vol. 2. Proceedings from the 1993 Henry B. and Jocelyn Wallace National Research Symposium on Talent Development (pp. 251-264). Dayton: Ohio Psychology Press.

Lohman, D. F. (2005). The role of nonverbal ability tests in identifying academically gifted students: An aptitude perspective. Gifted Child Quarterly, 49, 111-138.

Lohman, D. F., \& Korb, K. (2006). Gifted today but not tomorrow? Longitudinal changes in ITBS and CogAT scores during elementary school. Journal for the Education of the Gifted, 29, 451-484.

Loring-Meier, S., \& Halpern, D. F. (1999). Sex differences in visuopatial working memory: Components of cognitive processing. Psychonomic Bulletin \& Review, 6, 464-471.

Low, K. S. D., Yoon, M., Roberts, B. W., \& Rounds, J. (2005). The stability of vocational interests from early adolescence to middle adulthood: A quantitative review of longitudinal studies. Psychological Bulletin, 131, 713-737.

Lubinski, D. (2000). Scientific and social significance of assessing individual differences: "Sinking shafts at a few critical points." Annual Review of Psychology, 51, 405-444.

Lubinski, D. (2004). Introduction to the special section on cognitive abilities: 100 years after Spearman's (1904) "'General intelligence,' objectively determined and measured." Journal of Personality and Social Psychology, 86, 96-111.

Lubinski, D., \& Benbow, C. P. (2000). States of excellence. American Psychologist, 55, 137-150.

Lubinski, D., \& Benbow, C. P. (2006). Study of Mathematically Precocious Youth after 35 years: Uncovering antecedents for the development of math-science expertise. Perspectives on Psychological Science, 1, 316-345.

Lubinski, D., Benbow, C. P., \& Ryan, J. (1995). Stability of vocational interests among the intellectually gifted from adolescence to adulthood: A 15-year longitudinal study. Journal of Applied Psychology, 80, 90-94.
Lubinski, D., Benbow, C. P., Shea, D. L., Eftekhari-Sanjani, H., \& Halvorson, M. B. J. (2001). Men and women at promise for scientific excellence: Similarity not dissimilarity. Psychological Science, 12, 309317.

Lubinski, D., Benbow, C. P., Webb, R. M., \& Bleske-Rechek, A. (2006). Tracking exceptional human capital over two decades. Psychological Science, 17, 194-199.

Lubinski, D., \& Humphreys, L. G. (1990). Assessing spurious "moderator effects": Illustrated substantively with the hypothesized ("synergistic") relation between spatial visualization and mathematical ability. Psychological Bulletin, 107, 385-393.

Lubinski, D., Schmidt, D. B., \& Benbow, C. P. (1996). A 20-year stability analysis of the Study of Values for intellectually gifted individuals from adolescence to adulthood. Journal of Applied Psychology, 81, 443-451.

Lubinski, D., Webb, R. M., Morelock, M. J., \& Benbow, C. P. (2001). Top 1 in 10,000: A 10-year follow-up of the profoundly gifted. Journal of Applied Psychology, 86, 718-729.

Lupkowski-Shoplik, A., Benbow, C. P., Assouline, S. G., \& Brody, L. E. (2003). Talent searches: Meeting the needs of academically talented youth. In N. Colangelo \& G. A. Davis (Eds.), Handbook of gifted education (3rd ed., pp. 204-218). New York: Allyn \& Bacon.

Lykken, D. T. (1968). Statistical significance in psychological research. Psychological Bulletin, 70, 151-159.

Masters, M. S. (1998). The gender difference on the mental rotations test is not due to performance factors. Memory \& Cognition, 26, 444-448.

Meehl, P. E. (1978). Theoretical risks and tabular asterisks: Sir Karl, Sir Ronald, and the slow progress of soft psychology. Journal of Consulting and Clinical Psychology, 46, 806-834.

Meehl, P. E. (1990). Appraising and amending theories: The strategy of Lakatosian defense and two principles that warrant it. Psychological Inquiry, 1, 108-141.

Minor, L. L., \& Benbow, C. P. (1996). Construct validity of the SAT-M: A comparative study of high school students and gifted seventh graders. In C. P. Benbow \& D. Lubinski (Eds.), Intellectual talent: Psychometric and social issues (pp. 347-361). Baltimore: Johns Hopkins University Press.

Park, G., Lubinski, D., \& Benbow, C. P. (in press). Contrasting intellectual patterns for creativity in the arts and sciences: Tracking intellectually precocious youth over 25 years. Psychological Science.

Parsons, T. D., Larson, P., Kratz, K., Thiebaux, M., Bluestein, B., Buckalter, J. G., \& Rizzo, A. A. (2003). Sex differences in mental rotation and spatial rotation in a virtual environment. Neuropsychologia, 42, 555562.

Rao, C. R. (1948). Tests of significance in multivariate analysis. Biometrika, 35, 58-79.

Robinson, N. M. (1999). Necessity is the mother of invention: The roots of our "system" of providing educational alternatives for gifted students. Journal of Secondary Gifted Education, 10, 120-128.

Rounds, J., \& Tracey, T. J. G. (1996). Cross-cultural structural equivalence of RIASEC models and measures. Journal of Counseling Psychology, $43,310-329$.

Rounds, J. B., \& Armstrong, P. I. (2005). Assessment of needs and values. In S. D. Brown \& R. W. Lent (Eds.), Career development and counseling: Putting theory and research to work (pp. 305-329). Hoboken, NJ: Wiley.

Roy, S. N. (1938). A note on the distribution of the studentised $\mathrm{D}^{2}$-statistic. Sankhya: The Indian Journal of Statistics, 4, 373-380.

Rulon, P. J., Tiedmen, D. V., Tatsuoka, M. M., \& Langmuie, C. R. (1967) Multivariate statistics for personnel classification. New York: Wiley.

Scarr, S. (1996). How people make their own environments: Implications for parents and policy makers. Psychology, Public Policy, and Law, 2, $204-228$.

Scarr, S., \& McCartney, K. (1983). How people make their own environ- 
ments: A theory of genotype $\rightarrow$ environment effects. Child Development, 54, 424-435.

Schmidt, D. B., Lubinski, D., \& Benbow, C. P. (1998). Validity of assessing educational-vocational preference dimensions among intellectually talented 13-year-olds. Journal of Counseling Psychology, 45, 436-453.

Sechrest, L. (1963). Incremental validity: A recommendation. Educational and Psychological Measurement, 23, 153-158.

Shea, D. L., Lubinski, D., \& Benbow, C. P. (2001). Importance of assessing spatial ability in intellectually talented young adolescents: A 20-year longitudinal study. Journal of Educational Psychology, 93, 604-614.

Shurkin, J. N. (1992). Terman's kids. Boston: Little Brown.

Silverman, L. K. (1998). Personality and learning styles of gifted children. In J. VanTassel-Baska (Ed.), Excellence in educating: Gifted \& talented learners (pp. 29-65). Denver, CO: Love.

Smith, I. M. (1964). Spatial ability: Its educational and social significance. London: University of London Press.

Snow, C. P. (1965). The two cultures and a second look. London: Cambridge University Press.

Snow, R. E. (1994). A person-situation interaction theory of intelligence in outline. In A. Demetriou \& A. Efklides (Eds.), Intelligence, mind, and reasoning: Structure and development (pp.11-28). Amsterdam: Elsevier.

Snow, R. E. (1999). Commentary: Expanding the breadth and depth of admissions testing. In S. Messick (Ed.), Assessment in higher education (pp. 133-140). Hillsdale, NJ: Erlbaum.

Snow, R. E., Corno, L., \& Jackson, D., III. (1996). Individual differences in affective and conative functions. In D. C. Berliner \& R. C. Calfee (Eds.), Handbook of educational psychology (pp. 243-310). New York: Macmillan.

Snow, R. E., \& Lohman, D. F. (1989). Implications of cognitive psychol- ogy for educational measurement. In R. L. Linn (Ed.), Educational measurement (3rd ed., pp. 263-332). New York: Macmillan.

Spranger, E. (1928). Types of men. New York: Stechert-Hafner.

Stanley, J. C. (1996). In the beginning: The Study of Mathematically Precocious Youth. In C. P. Benbow \& D. Lubinski (Eds.), Intellectual talent (pp. 225-235). Baltimore: Johns Hopkins University Press.

Stanley, J. C. (2000). Helping students learn only what they don't already know. Psychology, Public Policy, and Law, 6, 216-222.

Tatsuoka, M. M. (1988). Multivariate analysis. New York: Macmillan.

Tyler, L. E. (1974). Individual differences. New York: Meredith.

Vandenberg, S. G., \& Kuse, A. R. (1978). Mental rotation: A group test of three-dimensional spatial visualization. Perceptual and Motor Skills, 47, $599-604$

VanTassel-Baska, J. (Ed.). (1998). Excellence in educating. Denver, CO: Love.

Wai, J., Lubinski, D., \& Benbow, C. P. (2005). Creativity and occupational accomplishments among intellectually precocious youth: An age 13 to age 33 longitudinal study. Journal of Educational Psychology, 97, 484-492.

Webb, R. M., Lubinski, D., \& Benbow, C. P. (2002). Mathematically facile adolescents with math-science aspirations: New perspectives on their educational and vocational development. Journal of Educational Psychology, 94, 785-794.

Wendler, C., Ninneman, A., \& Feigenbaum, M. (2001). Evaluating the appropriateness of the SAT I: Reasoning Test for seventh and eighth graders (Research Notes 12). New York: College Board.

Williamson, E. G. (1965). Vocational counseling. New York: McGrawHill.

Xie, Y., \& Shauman, K. A. (2003). Women in science. Cambridge, MA: Harvard University Press. 


\section{Appendix A}

\section{Phase 2: Preferences and Spatial Ability}

\section{Correlations Between Discriminant Function Scores Across Five Criterion Variables}

The intercorrelations of the first discriminant functions based on the five criterion variables are presented here. Scores on each discriminant function were calculated for all talent search participants. Correlations among individuals for whom longitudinal data were available appear below the diagonal in Table A1 (Study of Values [SOV] and spatial ability on the left side; general occupational themes of the Strong Interest Inventory [RIASEC] and

Table A1

Correlations Between Discriminant Function Scores Across Five Criterion Variables

\begin{tabular}{|c|c|c|c|c|c|c|c|c|c|c|}
\hline \multirow{2}{*}{$\begin{array}{l}\text { Function and } \\
\text { criterion variable }\end{array}$} & \multicolumn{5}{|c|}{$\mathrm{F}_{1}$} & \multicolumn{5}{|c|}{$\mathrm{F}_{2}$} \\
\hline & 1 & 2 & 3 & 4 & 5 & 1 & 2 & 3 & 4 & 5 \\
\hline \multicolumn{11}{|c|}{ DFAs based on values and spatial ability $(\mathrm{SOV}+\mathrm{S})$} \\
\hline $\mathrm{F}_{1}$ & & & & & & & & & & \\
\hline 1. Fav. & - & .89 & .95 & .92 & .95 & -.06 & -.22 & -.06 & -.09 & .07 \\
\hline 2. Least & .87 & - & .87 & .88 & .90 & -.27 & .00 & .06 & .14 & .38 \\
\hline 3. Leis. & .95 & .83 & - & .83 & .90 & -.04 & -.26 & .04 & .08 & .23 \\
\hline 4. Major & .92 & .88 & .82 & - & .99 & .01 & .12 & .19 & .07 & .02 \\
\hline 5. Occ. & .95 & .90 & .90 & .99 & - & .06 & .01 & .19 & .11 & .09 \\
\hline \multicolumn{11}{|l|}{$\mathrm{F}_{2}$} \\
\hline 1. Fav. & -.01 & -.25 & .13 & .00 & .08 & - & .00 & .63 & .42 & -.20 \\
\hline 2. Least & -.25 & .02 & -.32 & .08 & -.03 & -.14 & - & .66 & .58 & .25 \\
\hline 3. Leis. & -.11 & .06 & .01 & .12 & .14 & .57 & .62 & - & .92 & .40 \\
\hline 4. Major & -.16 & .10 & .00 & -.01 & .03 & .37 & .55 & .93 & - & .72 \\
\hline 5. Occ. & -.04 & .31 & .11 & -.05 & .01 & -.17 & .31 & .47 & .76 & - \\
\hline
\end{tabular}

DFAs based on interests and spatial ability (RIASEC + S)

$\mathrm{F}_{1}$

\begin{tabular}{|c|c|c|c|c|c|c|c|c|c|c|}
\hline 1. Fav. & - & .92 & .66 & .92 & .89 & .02 & .17 & -.44 & -.23 & -.16 \\
\hline 2. Least & .92 & - & .58 & .89 & .87 & -.08 & .05 & -.18 & .01 & .2 \\
\hline 3. Leis. & .69 & .56 & - & .48 & .81 & -.23 & -.17 & -.07 & .13 & -. \\
\hline 4. Major & .92 & .89 & .50 & - & .86 & -.06 & .26 & -.46 & -.04 &.- \\
\hline 5. Occ. & .89 & .85 & .82 & .87 & - & -.19 & .05 & -.17 & .19 & \\
\hline 1. Fav. & .00 & -.07 & -.17 & -.13 & -.21 & - & .73 & -.48 & -.64 &. \\
\hline 2. Least & .14 & .00 & -.14 & .20 & .02 & .65 & - & -.75 & .31 & \\
\hline 3. Leis. & -.38 & -.11 & -.01 & -.39 & -.17 & -.32 & -.73 & - & .31 & \\
\hline 4. Major & -.21 & .00 & .06 & .00 & .19 & -.66 & -.29 & .49 & - & \\
\hline 5. Occ. & -.10 & .27 & -.22 & .05 & .02 & -.54 & -.46 & .58 & .65 & \\
\hline
\end{tabular}

Note. Correlations are among discriminant function scores across five criterion variables. Correlations below the diagonal are based on subsets of the 547 talent search participants for whom 5-year follow-up surveys were secured; 540 cases were used in the analyses based on the Study of Values (SOV) and spatial ability, and 463 cases were used in the analyses based on RIASEC and spatial ability. Correlations above the diagonal are based on subsets of the 513 talent search participants for whom 5-year follow-up surveys were not secured (the replication sample); 476 cases were used in the analyses based on the SOV and spatial ability, and 418 cases were used in the analyses based on RIASEC and spatial ability. Although theoretically, $\mathrm{F}_{1}$ and $\mathrm{F}_{2}$ of the same criterion variable should be orthogonal, because of a small degree of item nonresponse, these cross-correlations diverged from zero somewhat. Boldface entries represent the cross-correlations among the first functions (across the five criterion variables) and among the second functions (across the five criterion variables). RIASEC $=$ general occupational themes of Strong Interest Inventory; $\mathrm{S}=$ spatial ability; $\mathrm{F}_{1}=$ first discriminant function; $\mathrm{F}_{2}=$ second discriminant function; Fav. $=$ favorite course; Least $=$ least favorite course; Leis. = preferred leisure activity; Major = undergraduate major; Occ. = anticipated occupation. 
Table A2

Correlations Between First Discriminant Function Scores for Analyses Based on the SOV and Spatial Ability Versus RIASEC and Spatial Ability Across Five Criterion Variables

\begin{tabular}{llllll}
\hline & \multicolumn{5}{c}{$\mathrm{F}_{1}(\mathrm{RIASEC}+\mathrm{S})$} \\
\cline { 2 - 6 } Function and criterion variable & 1 & 2 & 3 & 4 & 5 \\
\hline
\end{tabular}

$F_{1}$ scores of participants with longitudinal data

\begin{tabular}{llllll}
$\mathrm{F}_{1}(\mathrm{SOV}+\mathrm{S})$ & & & & & \\
1. Fav. & .78 & .69 & .66 & .72 & .77 \\
2. Least & .74 & .73 & .61 & .71 & .75 \\
3. Leis. & .73 & .67 & .72 & .66 & .80 \\
4. Major & .71 & .64 & .57 & .70 & .70 \\
5. Occ. & .74 & .67 & .64 & .72 & .77 \\
\hline
\end{tabular}

$F_{1}$ scores of participants without longitudinal data (replication sample)

\begin{tabular}{llllll}
$\mathrm{F}_{1}(\mathrm{SOV}+\mathrm{S})$ & & & & \\
1. Fav. & .79 & .73 & .66 & .73 & .78 \\
2. Least & .71 & .73 & .62 & .68 & .75 \\
3. Leis. & .74 & .73 & .72 & .68 & .81 \\
4. Major & .71 & .68 & .56 & .70 & .71 \\
5. Occ. & .75 & .72 & .63 & .73 & .77 \\
\hline
\end{tabular}

Note. Participants' scores on the first functions derived from the discriminant function analyses (DFAs) based on the Study of Values (SOV) and spatial ability (along left) were correlated with participants' scores on the first functions derived from the DFAs based on the RIASEC and spatial ability (along top). RIASEC = general occupational themes of Strong Interest Inventory; $\mathrm{S}=$ spatial ability; $\mathrm{F}_{1}=$ first discriminant function; Fav. = favorite course; Least = least favorite course; Leis. = preferred leisure activity; Major = undergraduate major; Occ. $=$ anticipated occupation.

spatial ability on the right); correlations among individuals for whom longitudinal data were not available appear above the diagonal (SOV and spatial ability on the left; RIASEC and spatial ability on the right).
In Table A2, participants' scores on the first functions derived from the discriminant function analyses (DFAs) based on the SOV and spatial ability were correlated with the first functions derived from the DFAs based on the RIASEC and spatial ability.

\section{Appendix B}

\section{Phase 3: Preferences and Mathematical, Verbal, and Spatial Abilities}

\section{Correlations Between Discriminant Function Scores Across Five Criterion Variables}

The intercorrelations of the first discriminant functions based on the five criterion variables are presented here. Scores on each discriminant function were calculated for all talent search participants. Correlations among the function scores of individuals for whom longitudinal data were available appear below the diagonal in Table B1 (Study of Values [SOV] and abilities on the left; general occupational themes of the Strong Interest Inventory [RIASEC] and abilities on the right). Correlations among the function scores of individuals for whom longitudinal data were not available appear above the diagonal (SOV and abilities on the left; RIASEC and abilities on the right).

In Table B2, participants' scores on the first functions derived from the discriminant function analyses (DFAs) based on the SOV and abilities were correlated with the first functions derived from the DFAs based on the RIASEC and abilities. 
Table B1

Correlations Between Discriminant Function Scores Across Five Criterion Variables

\begin{tabular}{|c|c|c|c|c|c|c|c|c|c|c|}
\hline \multirow{2}{*}{$\begin{array}{c}\text { Function and } \\
\text { criterion variable }\end{array}$} & \multicolumn{5}{|c|}{$\mathrm{F}_{1}$} & \multicolumn{5}{|c|}{$\mathrm{F}_{2}$} \\
\hline & 1 & 2 & 3 & 4 & 5 & 1 & 2 & 3 & 4 & 5 \\
\hline \multicolumn{11}{|c|}{ DFAs based on values and abilities $(\mathrm{SOV}+\mathrm{M}+\mathrm{V}+\mathrm{S})$} \\
\hline \multicolumn{11}{|l|}{$\mathrm{F}_{1}$} \\
\hline 1. Fav. & - & .78 & .89 & .79 & .84 & -.05 & -.01 & -.01 & -.35 & -.13 \\
\hline 2. Least & .81 & - & .69 & .87 & .87 & .21 & .11 & .41 & .16 & .02 \\
\hline 3. Leis. & .89 & .69 & - & .74 & .84 & -.17 & .27 & -.02 & -.33 & .16 \\
\hline 4. Major & .78 & .86 & .69 & - & .96 & .01 & .26 & .41 & .05 & .06 \\
\hline 5. Occ. & .85 & .89 & .81 & .95 & - & -.07 & .18 & .36 & -.05 & -.02 \\
\hline \multicolumn{11}{|l|}{$\mathrm{F}_{2}$} \\
\hline 1. Fav. & .00 & .21 & -.10 & .05 & .00 & - & -.08 & .26 & .76 & .27 \\
\hline 2. Least & -.05 & .00 & .23 & .24 & .13 & -.09 & - & .22 & .29 & .76 \\
\hline 3. Leis. & -.02 & .35 & -.03 & .39 & .35 & .21 & .22 & - & .64 & .11 \\
\hline 4. Major & -.35 & .09 & -.35 & .03 & -.07 & .77 & .24 & .59 & - & .38 \\
\hline 5. Occ. & -.07 & -.06 & .24 & .09 & .01 & .19 & .79 & .07 & .24 & - \\
\hline
\end{tabular}

DFAs based on interests and abilities (RIASEC $+\mathrm{M}+\mathrm{V}+\mathrm{S}$ )

$\mathrm{F}_{1}$

\begin{tabular}{|c|c|c|c|c|c|c|c|c|c|c|}
\hline 1. Fav. & - & .74 & .80 & .79 & .85 & .08 & .16 & -.36 & .06 & .0 \\
\hline 2. Least & .80 & - & .66 & .76 & .86 & .06 & -.08 & -.06 & -.40 & -.15 \\
\hline 3. Leis. & .81 & .67 & - & .68 & .83 & -.07 & -.12 & -.12 & .08 & \\
\hline 4. Major & .83 & .80 & .67 & - & .83 & -.27 & .03 & -.51 & .02 & \\
\hline 5. Occ. & .88 & .85 & .81 & .85 & - & -.06 & .05 & -.33 & -.17 &.- \\
\hline 1. Fav. & -.02 & -.02 & -.17 & -.24 & -.09 & - & -.23 & .59 & -.46 & \\
\hline 2. Least & .20 & .00 & -.11 & .11 & .14 & -.21 & - & -.47 & .33 & \\
\hline 3. Leis. & -.31 & -.03 & -.02 & -.44 & -.31 & .47 & -.51 & - & -.34 & - \\
\hline 4. Major & .07 & -.31 & .15 & -.02 & -.16 & -.53 & .27 & -.21 & - & \\
\hline 5. Occ. & .10 & -.09 & .22 & .13 & .01 & -.52 & .44 & -.35 & .46 & \\
\hline
\end{tabular}

Note. Correlations are among discriminant function scores across five criterion variables. Correlations below the diagonal are based on subsets of the 547 talent search participants for whom 5-year follow-up surveys were secured; 223 cases were used in the analyses based on the Study of Values (SOV) and three ability measures, and 211 cases were used in the analyses based on RIASEC and abilities. Correlations above the diagonal are based on subsets of the 513 talent search participants for whom 5-year follow-up surveys were not secured (the replication sample); 166 cases were used in the analyses based on the SOV and abilities, and 157 cases were used in the analyses based on RIASEC and abilities. Boldface entries represent the cross-correlations among the first functions (across the five criterion variables) and among the second functions (across the five criterion variables). RIASEC $=$ general occupational themes of Strong Interest Inventory; $\mathrm{M}=$ mathematical ability; $\mathrm{V}=$ verbal ability; $\mathrm{S}=$ spatial ability; $\mathrm{F}_{1}=$ first discriminant function; $\mathrm{F}_{2}=$ second discriminant function; Fav. = favorite course; Least $=$ least favorite course Leis. $=$ preferred leisure activity; Major $=$ undergraduate major; Occ. $=$ anticipated occupation. 
Table B2

Correlations Between First Discriminant Function Scores for Analyses Based on the SOV and Three Ability Measures Versus RIASEC and Three Ability Measures Across Five Criterion Variables

\begin{tabular}{|c|c|c|c|c|c|}
\hline \multirow{2}{*}{$\begin{array}{c}\text { Function and } \\
\text { criterion variable }\end{array}$} & \multicolumn{5}{|c|}{$\mathrm{F}_{1}(\mathrm{RIASEC}+\mathrm{M}+\mathrm{V}+\mathrm{S})$} \\
\hline & 1 & 2 & 3 & 4 & 5 \\
\hline \multicolumn{6}{|c|}{$\mathrm{F}_{1}$ scores of participants with longitudinal data } \\
\hline \multicolumn{6}{|l|}{$\mathrm{F}_{1}(\mathrm{SOV}+\mathrm{M}+\mathrm{V}+\mathrm{S})$} \\
\hline 1. Fav. & .80 & .62 & .73 & .70 & .84 \\
\hline 2. Least & .63 & .72 & .65 & .66 & .84 \\
\hline 3. Leis. & .75 & .63 & .78 & .69 & .86 \\
\hline 4. Major & .60 & .66 & .60 & .70 & .74 \\
\hline 5. Occ. & .70 & .70 & .69 & .75 & .85 \\
\hline
\end{tabular}

$F_{1}$ scores of participants without longitudinal data (replication sample)

\begin{tabular}{|c|c|c|c|c|c|}
\hline \multicolumn{6}{|c|}{$\mathrm{F}_{1}(\mathrm{SOV}+$} \\
\hline 1. Fav. & .78 & .56 & .71 & .67 & .79 \\
\hline 2. Least & .58 & .73 & .70 & .64 & .83 \\
\hline 3. Leis. & .74 & .62 & .75 & .71 & .86 \\
\hline 4. Major & .59 & .64 & .64 & .70 & .75 \\
\hline 5. Occ. & .68 & .66 & .71 & .74 & .83 \\
\hline
\end{tabular}

Note. Correlations among participants' scores on the first functions derived from the discriminant function analyses (DFAs) based on the Study of Values (SOV) and three ability measures (along left) were correlated with participants' scores on the first functions derived from the DFAs based on the RIASEC and three ability measures (along top). RIASEC $=$ general occupational themes of Strong Interest Inventory; $\mathrm{M}=$ mathematical ability; $\mathrm{V}$ = verbal ability; $\mathrm{S}=$ spatial ability; $\mathrm{F}_{1}=$ first discriminant function; Fav. = favorite course; Least = least favorite course; Leis. = preferred leisure activity; Major $=$ undergraduate major; Occ. $=$ anticipated occupation.

Received July 29, 2005

Revision received December 19, 2006

Accepted December 19, 2006 